\title{
Application of New 3-D Analytical Model for Directional Wellbore Friction
}

\author{
Mohammad Fazaelizadeh \\ Schulich School of Engineering, University of Calgary \\ 2500 University Drive NW, Calgary, T2N 1N4, Canada \\ Tel: 1-403-210-9803 E-mail: mfazaeli@ucalgary.ca \\ Geir Hareland \\ Schulich School of Engineering, University of Calgary \\ 2500 University Drive NW, Calgary, T2N 1N4, Canada \\ Tel: 1-403-210-6264 E-mail: gharelan@ucalgary.ca
}

\author{
Bernt S. Aadnoy \\ University of Stavanger \\ 4036 Stavanger, Norway \\ Tel: 47-51-832256 E-mail: bernt.aadnoy@uis.no
}

\begin{abstract}
Wellbore friction modeling is considered an important assessment to aid realtime drilling analysis. It predicts and prevents drilling troubles such as tight holes, cutting bed accumulations and differential sticking.

This paper presents a new 3-dimensional wellbore friction model for drilling horizontal and extended reach wells. The model can be easily applied for all wellbore shapes such as straight, curved and also a combination of different curved sections. The model has the capability of calculating torque and drag for different drilling modes such as rotating, tripping and a combination of modes such as reaming and back reaming operations, and for workover and completion operations.

Different effects such as contact surface and hydrodynamic viscous force are included in the model, and their impacts on the results were investigated. To show the application of the model, a field case study was used and modeling results from field data were analyzed.
\end{abstract}

Keywords: 3-D Wellbore Friction, Modeling, Realtime, Drilling Analysis, Torque and Drag, Field Case, Hydrodynamic Viscous Force, Contact Surface

\section{Introduction}

Drillstring torque and drag are critical issues which limit the drilling industry to go beyond a certain measured depth. Surface torque is the moment required to rotate the entire drillstring and the bit on bottom. This moment is used to overcome the rotational friction against the wellbore, the viscous force between pipe string and drilling fluid, and the bit torque. The drag is the incremental force needed for pulling or lowering the drillstring through the hole. This force is used to overcome the axial friction between the pipe and the wellbore and the hydrodynamic viscous force between the pipe string and the drilling fluid.

Eek-Olsen et al. (1994) showed the development from a $3 \mathrm{~km}$ horizontal reach well to beyond $7 \mathrm{~km}$. In the "Wytch Farm" project, extended reach length carried to more than $10 \mathrm{~km}$ (Payne et al., 1994). The wellbore friction is one of the major issues in extended reach wells. 
One of the first contributors to the understanding of well friction was Johancsik et al. (1984) who established the simplified model to predict well friction in deviated wellbores. The model makes no distinction between cased and openhole friction coefficients. Optimal well path design was also addressed by Sheppard et al. (1987), who showed that an undersection trajectory reduces wellbore friction compared to a conventional tangent section. Maidla and Wojtanowicz $(1987$, a) presented a method to evaluate an overall friction coefficient between the wellbore and the casing string. The computation is based on matching field data and modeling by assuming a friction coefficient. The equation for predicting surface hook loads are derived from the respective governing differential equations. Maidla and Wojtanowicz $(1987$, b) also presented a new procedure for wellbore drag prediction. The procedure employed iteration over directional survey points, numerical integration between the stations and mathematical models of axial loads within pipe movement in the wellbore. The model considers some new effects such as hydrodynamic viscous drag, contact surface and dogleg angle.

Aadnoy and Andersen (2001) developed analytical solutions to calculate wellbore friction for different well geometries. These solutions gave better insight into the frictional behavior throughout the well, and each geometry required individual equations. Mason and Chen (2007) provided an assessment of limitations of the various torque and drag model and appraises their validity. The torque and drag model formulation has been reviewed by Robert et al. (2007) in the context of a large displacement equilibrium analysis. More recently, Aadnoy et al. (2009) modeled entire wells by two sets of equations for straight and curved sections. A curved equation is based on the absolute dogleg of the wellbore and therefore applicable for fully 3-dimensional wells.

\section{Torque and Drag Model}

The basic torque and drag model include equations which were developed by Aadnoy et al. (2009). The soft string model is so called because it ignores any tubular stiffness effects. This means that the pipe is behaving like a heavy cable lying along the wellbore which implies that axial tension and torque forces are supported by the string and contact forces are supported along the wellbore.

The derived equations define the hook loads for pulling and lowering operations and also the torque for a string in a wellbore. There are two sets of equations, one for straight well sections and another for curved sections.

\subsection{Torque and Drag along a Straight Section}

For the drag along the straight section, the Coulomb friction model is used. For the drillstring element with the length of $\Delta L$, the force required for moving this element is:

$$
\Delta F=\beta w \Delta L(\cos \alpha \pm \mu \sin \alpha)
$$

The first term of equation (1) is referred to as the weight of the element and the second term is referred to as additional frictional force required for moving the pipe element. The plus sign defines pulling of the pipe element, whereas the minus sign defines lowering of the pipe element. If $\alpha$ is equal to zero, it means the pipe section is in a vertical position and the friction term will be diminished. If $\alpha$ is equal to 90 degrees, it means the pipe section is in a horizontal position and the weight term will be diminished.

Once the drillstring description, the survey data, and the friction coefficient are specified, the calculation starts at the bottom of the drillstring and proceed stepwise upward. The same approach will be used for straight and curved sections.

If the string divided into $n$ elements, $F_{i-1}$ is the force at bottom of each element and $F_{i}$ is the force at the top of each element which adds up to the length of the entire section. The well can be filled with different mud weights which result in the different buoyancy factor $\beta_{\mathrm{i}}$ for different sections. If the well is filled with only one drilling fluid with uniform weight, all buoyancy factors $\beta \mathrm{i}$ will be equal. Also, the drillstring consists of different components with different unit weights $w_{i}$ such as drill pipe, heavy weight drill pipe etc, which should be taken in consideration for hook load calculations.

For the friction coefficient $\mu$ there are two methods for the torque and drag calculation. The first is assuming one friction coefficient for the entire well for both cased and open sections, trying to get the best match with measured hook loads. The second method is assuming different friction coefficients for cased hole and open hole. In Equation (2) all $\mu \mathrm{s}$ can be equal or switched from open hole to cased hole friction coefficients. The general equation for an entire straight section consisting of $n$ different pipes can be written as:

$\sum_{i=2}^{n} F_{i}=\sum_{i=2}^{n} F_{i-1}+\sum_{i=2}^{n}\{\beta w \Delta L \times(\cos \alpha \pm \mu \sin \alpha)\}_{i}$

When the friction coefficient $\mu$ is equal to zero, Equation (2) shows the static weight of a straight section during the drilling operation.

Torque or rotational friction is defined as the friction coefficient multiplied by normal moment. Equation (3) shows the 
applied torque on a straight section.

$T=\mu \times \beta w \Delta L r \sin \alpha$

For $\alpha$ equal to zero in a vertical section, no torque applies. Also for $\alpha$ equal to 90 degrees in a horizontal section, the maximum torque applies. Equation (4) shows the entire torque along the drillstring in a straight section.

$\sum_{i=2}^{n} T_{i}=\sum_{i=2}^{n} T_{i-1}+\sum_{i=2}^{n}\{\mu \times \beta w \Delta L r \sin \alpha\}_{i}$

It should be mentioned that the drillstring in a straight section may consist of different components which may have different tool joint radii $r_{i}$. For $i$ equal to $2, T_{1}$ represents the bit torque.

\subsection{Torque and Drag along a Curved Section}

Aadnoy et al. (2009) developed new torque and drag equations for curved sections. For curved borehole sections, the normal contact force between string and hole is strongly dependent on the axial pipe loading. This is therefore a tension dominated process. In the derivation, they assumed that the pipe is weightless when they compute the friction, but add the weight at the end of the bend.

During the drilling operation, the wellbore is surveyed at regular intervals. The main outputs are the wellbore inclination and the geographical azimuth. These data are used to calculate depth and horizontal displacement. Furthermore, the dogleg angle $\theta$ depends both on the wellbore inclination and the azimuth. Because the pipe will contact either the high side or the low side of the curved wellbore, its contact surface is given by the dogleg plane. The dogleg angle is defined for each hole section as follow:

$\cos \theta_{i}=\sin \alpha_{i} \sin \alpha_{i-1} \cos \left(\phi_{i}-\phi_{i-1}\right)+\cos \alpha_{i} \cos \alpha_{i-1}$

For build-up, drop-off, side bends or combination of them, the axial force for a pipe element $i$ equal to 2 becomes:

$F_{2}=F_{1} \times e^{ \pm \mu_{2}\left|\theta_{2}\right|}+\beta_{2} w_{2} \Delta L_{2} \times\left\{\frac{\sin \alpha_{2}-\sin \alpha_{1}}{\alpha_{2}-\alpha_{1}}\right\}$

Where the plus sign defines pulling of the pipe element, whereas the minus sign defines lowering of the pipe element in a curved section. For an entire curved section the drag Equation (7) can be used:

$\sum_{i=2}^{n} F_{i}=\sum_{i=2}^{n}\left[F_{i-1} \times e^{ \pm \mu_{i}\left|\theta_{i}\right|}\right]+\sum_{i=2}^{n}\left\{\beta_{i} w_{i} \Delta L_{i} \times\left[\frac{\sin \alpha_{i}-\sin \alpha_{i-1}}{\alpha_{i}-\alpha_{i-1}}\right]\right\}$

When the friction coefficient is assumed equal to zero, Equation (7) will show the static weight of the entire curved section. The torque for the bend element $i$ equal to 2 is defined as follows:

$T_{2}=\mu_{2} \times r_{2} F_{1}\left|\theta_{2}-\theta_{1}\right|$

Equation (9) shows torque calculation for an entire curve section

$\sum_{i=2}^{n} T_{i}=\sum_{i=2}^{n} \mu_{i} \times r_{i} F_{i-1}\left|\theta_{i}-\theta_{i-1}\right|$

To summarize, wellbore frictions for any shape can thus be computed by dividing the well into straight and curved elements and then forces and torques are added up starting from the bottom of the string to the top. The summation is based on each change in wellbore geometry or pipe size.

\section{Effect of Other Parameters on Torque and Drag Values}

The friction coefficient has an important role in torque and drag modeling calculations which may cause some confusion. It is defined in terms of roughness between the drillstring and the wellbore wall, but there are always some other contributions that have influenced the true value of torque and drag, such as:

$>$ pipe stiffness

$>$ key seat

$>$ hole cleaning

$>$ BHA, stabilizer, centralizer

$>$ pipe couplings

$>$ formation properties 
$>$ wellbore instabilities

$>$ combined axial motion and rotation

$>$ hydrodynamic viscous drag force

$>$ contact surface

Pipe stiffness is not included in this soft string model. The soft string means that the drillstring is behaving like a heavy cable lying along the wellbore. Axial and rotational forces are supported by the string and contact forces are supported by the wellbore.

Poor hole cleaning in extended reach wells can form cutting beds. Cutting beds is a mechanical wellbore obstacle which leads to an increase in torque and drag. Poor hole cleaning can be prevented by proper mud and hydraulic design and drillstring rotation from surface.

BHA, stabilizer, and centralizer increase the string stiffness and result in higher wellbore friction for wells with short build radius. For torque and drag modeling in these wells it is possible to consider some additional value of torque and drag for BHA, stabilizer and centralizer.

Formation properties also have an effect on measured hook loads. Different formations have different roughness and lubricity which has a direct effect on the value of torque and drag. Also, if the formation pressure is smaller than the hydraulic pressure, circulation loss may occur and may result in loss of lubricity. If this pressure difference becomes great, differential sticking is probable to happen.

Wellbore instabilities can be seen as sloughing and tight hole, which have a great effect on the value measured hook loads. These can be avoided by proper mud design, reaming operations and running casing. Some of the effects above will now be discussed in further detail.

\subsection{Effect of Combined Axial Motion and Rotation Effect}

During the tripping operation an overpull may occur due to tight hole conditions. The remedy action is typically to rotate the drillstring while pulling or lowering. In the oilfield, a considerable difference can be observed between measured hook loads while tripping in/out and reaming/back reaming operations.

Aadnoy and Andersen (2001) showed how the frictional capacity is divided into the two directions, axial and rotational movements. Aadnoy et al. (2009) developed a simple model for combined motions which shows how rotation will reduce drag while lowering and pulling the pipe in the wellbore. During combined motion, the axial velocity is $V_{h}$, and the tangential pipe speed is $V_{r}$ which give a resultant velocity of $V$ as shown in Figure 1.

The angle between the two velocities is defined as follow:

$\psi=\tan ^{-1}\left(\frac{V_{h}}{V_{r}}\right)=\tan ^{-1}\left(\frac{60 \times V_{h}}{2 \pi N_{r} \times r}\right)$

When $\psi$ equal to 90 degrees, it means that there is no rotation during axial movement, and when $\psi$ equal to 0 degrees means there is no axial movement during rotation. Table 1 shows a summary of possible situations for combined motion.

Tripping speeds and rotational speeds can be varied during reaming and back reaming operations, thus it may have different $\psi_{\imath}$ values for each reamed points. The torque and drag equations can be defined for combined motion as follows:

For entire straight section:

$$
\begin{aligned}
& \sum_{i=2}^{n} F_{i}=\sum_{i=2}^{n} F_{i-1}+\sum_{i=2}^{n}\{\beta w \Delta L \cos \alpha\}_{i} \pm \sum_{i=2}^{n}\{\beta w \Delta L \sin \alpha \times \mu \times \sin \psi\}_{i} \\
& \sum_{i=2}^{n} T_{i}=\sum_{i=2}^{n}\{\mu \times \beta w \Delta L r \sin \alpha \times \cos \psi\}_{i}
\end{aligned}
$$

For entire curved section:

$$
\sum_{i=2}^{n} F_{i}=\sum_{i=2}^{n} F_{i-1}+\sum_{i=2}^{n}\left[F_{i-1} \times\left(e^{ \pm \mu_{i}\left|\theta_{i}\right|}-1\right) \times \sin \psi_{i}\right]+\sum_{i=2}^{n}\left\{\beta_{i} w_{i} \Delta L_{i} \times\left[\frac{\sin \alpha_{i}-\sin \alpha_{i-1}}{\alpha_{i}-\alpha_{i-1}}\right]\right\}
$$




$$
\sum_{i=2}^{n} T_{i}=\mu_{i} \times r_{i} F_{i-1}\left|\theta_{i}\right| \times \cos \psi_{i}
$$

\subsection{Effect of Hydrodynamic Viscous Force}

Viscous-drag surges results from moving pipe and by changing the annular mud velocity. The moving pipe walls transport mud in the direction of the motion of the pipe, and at the same time the volume of the pipe displaces mud in an opposite direction to the pipe's motion. The annular mud velocity required to calculate viscous pressure gradient depends upon several factors such as:

$>$ the nature of the fluid (whether Newtonian or non-Newtonian)

$>$ flow regimes (laminar or turbulent)

$>$ the pipe velocity

$>$ open ended or close ended string (check valve (float) present in the string)

Maidla and Wojtanowicz (1987, a) showed the hydrodynamic viscous force effect by calculating surge or swab pressures associated with pipe movement in the wellbore. They presented a viscous pressure gradient for each pipe element which can be calculated by equations in Appendix $A$. According to this, the hydrodynamic viscous drag force can be calculated by equation (15):

$$
F_{D}=\frac{\pi}{4} \sum_{i=1}^{n}\left(\frac{\Delta P}{\Delta L}\right)_{i} \Delta L_{i} d_{i}^{2}
$$

\subsection{Effect of Contact Surface}

Maidla and Wojtanowicz $(1987$, b) also presented contact surface correction factors to consider in drag calculations. The correction factor, $C_{s}$, represents an effect of the contact surface between the pipe and the wellbore due to larger curve surface contact. They showed that when a cylinder with outer diameter $d$ moves through a pipe with the inner diameter $D$, when applying a normal force $F_{N}$, the drag force will be as follow:

$$
F_{D}=\frac{4}{\pi} \times \mu \times F_{N}
$$

Equation (16) means that real drag force for curve contact surface is $4 / \pi$ times larger than for a flat contact surface. In this case, the correction factor is $4 / \pi$. In case of pipe string and wellbore, the string outer diameter is smaller than the wellbore diameter and the drag force can be written as:

$$
F_{D}=C_{S} \times \mu \times F_{N}
$$

The correction factor values vary between 1 and $4 / \pi$ and depend upon contact surface angle $\gamma$ which varies between $0^{\circ}$ and $90^{\circ}$. Contact surface angle $\gamma_{i}$ is mainly dependent on wellbore and string outer diameters. Maidla and Wojtanowicz $(1987$, a) show how contact surface effect can be calculated for each point.

$$
C s_{i}=\frac{2}{\pi} \gamma_{i}\left(\frac{4}{\pi}-1\right)+1
$$

Appendix $B$ shows how contact surface angle $\gamma$ can be calculated. To include contact surface effect in the torque and drag equations, it should be multiplied by the friction coefficient. Obviously, if this effect is ignored in calculations, a larger friction coefficient should be used to match calculated data with measured data.

\section{Measured Hook Load Treatment}

In the oilfield a weight indicator is used to show the approximate hook load. The weight indicator is a hydraulic load cell either attached to or integrated into the dead line anchor. The hook load $W$, displayed by the weight indicator which is assumed to be equal to the number of lines between blocks $N$, multiplies by dead line tension $F_{d l}$.

$$
W=F_{d l} \times N
$$

Equation 19 is an accepted industry method to calculate hook load. It does not account for sheave friction and does not consider the difference between static and dynamic conditions. Luke and Juvkam-Wold (1993) showed that true hook load depends on sheave friction and the direction of block movement. They proved that true line tension from dead-line tension readings does not give correct load, but with some corrections these tension readings can be used.

When tripping out, the tension gradually reduces from the fast-line to the dead-line. In this way, the fast-line would have the highest tension and dead-line would have the lowest tension. It means that the weight indicator will display 
low when the drillstring is being pulled out. When tripping in, the highest line tension is the dead-line and the lowest tension is in the fast-line. It results in high readings by the weight indicator when running the drillstring in the hole.

Dangerfield, (1987) made a mathematical analysis of the frictional resistance on the hoisting system. In his analysis, he proposed that two types of dead-line sheaves existed: active and inactive. Active dead-line sheave is the sheave in the crown block which the dead-line passes over and goes back to the traveling block. It is free to rotate. It is also known as friction sheave due to the difference between the tensions in the lines on either side of the sheave. For the inactive dead-line sheave, which is known as frictionless sheave, the tensions in the lines on both sides of the sheave are the same.

Appendix $C$ presents equations which were derived by Luke and Juvkam-Wold, (1993) for hook load prediction for different dead line sheaves and drillstring movement. They showed that the average sheave efficiency $e$ ranged from $96 \%$ to $99 \%$.

\section{Application of the New Improved Model}

To verify applicability of the new improved model, the following field case will be discussed. Records from this field case are from January 2009 on an onshore rig in Alberta, Canada. The horizontal departure and vertical section of the well are shown in Figure 2. A $95 / 8$ inch surface casing string was run to $2090 \mathrm{ft}$. An intermediate 7 inch casing was set at $7500 \mathrm{ft}$ and then $61 / 8 \mathrm{inch}$ bit was used for drilling horizontal section to reach the target.

\subsection{Case 1: Analysis of Tripping out}

This example will demonstrate the application of the model for tripping the drillstring out. Drillstring total length is $10995 \mathrm{ft}$ as shown in Figure 3. In a horizontal well the drillstring must be forced into the wellbore. Here, the 4 inch heavy weight drill pipes were placed in the vertical section to provide weight. The complete drillstring in the horizontal section is placed in compression during drilling. The adjusted weight for 4 inch drillpipe and 4 inch heavy weight drill pipes are $17.71 \mathrm{lb} / \mathrm{ft}$ and $29.92 \mathrm{lb} / \mathrm{ft}$ respectively. The well is filled with drilling fluid with weight of $8.9 \mathrm{lb} / \mathrm{gallon}$. For this case there is no change in azimuth which implies that dogleg changes in Equation 5 is equal to the changes in inclination.

Figure 4 shows measured hook loads while tripping out. The measured hook load values are the function of drillstring length, well geometry and drillstring configuration. Different well geometries and different drillstring configurations in the vertical section show different measured hook load trends. Figure 4 also shows hook load measurements when the entire drillstring weight is in slips during connection times. They represent the weight of hoisting assembly at the surface without precise calibration. The data was recorded when the bit depth was at $740 \mathrm{ft}$.

In this model, usually friction coefficients vary from 0.1 to 0.4 to match with normal field data. Figure 5 shows a comparison between measured and calculated hook load values for different friction coefficients. Figure 5 shows that with a low value of friction factor of 0.1 , there is still 6 percent deviation from field data at $7700 \mathrm{ft}$.

For quality control of field data, the tripping data should be compared with static weight of the drillstring. The static weight means the weight of the drillstring when no friction is applied to the drillstring movement. Figure 6 shows measured hook loads that have smaller values than the static weight data, which is obviously wrong.

The field data related to tripping out should always be greater than static weight due to friction between the drillstring and the wellbore. The field data have been recorded based on equation 19, which is known as accepted industry method. This industry method records lower dead-line tension during tripping-out due to sheave friction being ignored. If sheave efficiency is assumed to be at least $99 \%$ for 10 drilling lines between blocks, then the corrected field data is shown in Figure 7. The error between field data and modeling results is reduced to $2 \%$. This error can be referred to assumptions which are made for deriving the equations.

It is good practice to compare field data with static weight data to make sure the quality of measured data is acceptable. Also, using different torque and drag models can be helpful for data quality control. Figure 8 shows why it is necessary to do quality control of measured field data. It shows two subsequent tripping out hook load records due to trouble shooting of MWD tool after drilling three feet. This comparison shows why the weight indicator calibration and quality of recorded data is important for realtime torque and drag analysis.

\subsection{Case 2: Analysis of Tripping in}

Figure 9 shows tripping in from surface to depth, $10760 \mathrm{ft}$. The well is the same as (Figure 2). The drillstring configuration is the same as Case 1 in which 4 inch heavy weight drill pipes were placed in the vertical section to provide weight to push the drillstring into the horizontal section. The well is filled with the same drilling fluid with the weight of $8.91 \mathrm{lb} /$ gallon. The field data in Figure 9 were treated by assuming sheave efficiency as much as $99 \%$ for 10 drilling lines between the blocks.

Figure 9 shows a perfect match between calculated and measured hook loads while tripping in from surface to $9100 \mathrm{ft}$. 
In the interval between 9100 and $10400 \mathrm{ft}$, there is a significant reduction in measured hook loads exceeding expected values. This reduction can be attributed to many factors such as spring effect, stabbing effect and ledge effect. These are reasons why usually the friction coefficient used for tripping in is greater than the friction coefficient used for tripping out. The common solution to cure this problem is reaming and back reaming operations to reduce these effects and make a smoother path with lower friction coefficient for drillstring movement. Agitators can also be used to release compression forces along drillstring in a horizontal section.

Sensitivity analysis of the friction coefficient can be helpful in this scenario. It means to try to get a perfect match between measured and calculated hook loads by assuming any value of friction coefficient. If the difference between two subsequent friction coefficients is very small, it means there is no problem for string movement. If the difference is considerable, it implies that something is wrong and a quick remedial action should be considered. Therefore, sensitivity analysis of friction coefficient could be helpful to predict any problem during drilling operation. Figure 10 shows trouble intervals found by sensitivity analysis of friction coefficient while tripping in.

\subsection{Case 3: Analysis of Torque and Drag during Reaming Operation}

The sliding mode was used to drill this part of the well which means using mud motor instead of the rotary table at the surface and the mud motor. Obviously, there are not surface torque records during this drilling operation. The surface torque is only recorded during reaming and back reaming operations. As discussed in Case 2, there was some resistance against string movement while tripping in from $9100 \mathrm{ft}$ to the bottom. To reduce this resistance against axial movement, the drillstring was rotated from surface. Therefore, surface torque was recorded during reaming and back reaming operations for this interval.

Figure 11 compares measured and calculated surface torque during reaming and back reaming operations. During the reaming operation, tripping and rotary speeds were $0.5 \mathrm{ft} / \mathrm{sec}$ and $55 \mathrm{rpm}$ respectively. The majority of the field data is seen located between reaming and back reaming calculated data. The measured torque data shows high fluctuations which can refer to drillstring dynamics such as slip/stick, restoring moment, torsional resistance and axial and lateral vibrations. It is usually difficult to compare calculated torque to measured data with high fluctuations. To make it easier, the measured data should be averaged out over a short interval. Average measured data over reamed interval has been shown in Figure 11.

Also, the remedial action for overpull during tripping out is typically drillstring rotation. Aadnoy et al. (2009) derived a simple model for combined motion which shows the effect of rotation on drag force reduction in the well. In the oilfield, the weight indicator shows considerable difference between drag force generated by tripping in/out and reaming/back reaming operations. Figure 12 shows effect of pipe rotation on calculated hook loads during reaming and back reaming operations. As discussed in previous sections, the wellbore friction was split into rotational and axial friction. By increasing one of them, the other will decrease. For example, at a constant pipe rotary speed, the torque values will decrease due to increase of tripping speed which leads to increase of axial friction. Figure 13 shows the effect of tripping speed on calculated torque at a constant rpm. Also, if pipe rotations speed up at constant tripping speed during reaming operation, it will result in higher torque values as shown in Figure 14.

\subsection{Case 4: Effect of Contact Surface}

Equation B-5 in Appendix $B$ was used to consider effects of contact surface, $\mathrm{C}_{\mathrm{S}}$ in torque and drag calculations. The data required to include this effect are wellbore diameter and pipe string outer diameter. In this case, a 7 inch casing was set at $7500 \mathrm{ft}$ and then horizontal reach was drilled by $61 / 8$ inch bit size. Both 4 inch drillpipe and 4 inch heavy weight drillpipe have the same adjusted outer diameter of $4.1 \mathrm{inch}$. The $C$ calculated for open hole and cased hole is 1.16 and 1.15 respectively. Figure 15 shows effect of contact surface on calculated hook loads while tripping in/out. When the drillstring is at the bottom of the well, effect of contact surface on hook load value during tripping in/out are 0.3 and 1.5 percent respectively. Effect of contact surface on torque calculations is more sensible because the torque values related to lowering and pulling increased 5 and 20 percent respectively. Figure 16 compares torque values before and after considering effect of contact surface for torque calculations.

\subsection{Case 5: Effect of Hydrodynamic Viscous Drag Force}

Hydrodynamic viscous drag force is defined as the friction force between the pipe string and the drilling fluid, which resist against pipe movement. It depends on drilling fluid properties, tripping velocity, flow regime, pipe outer diameter and wellbore diameter. Here, the drillstring configuration and the well specifications are the same as previous field cases. Figure 17 shows effect of mud rheology on hydrodynamic viscous drag force. The more viscous drilling fluid results the more viscous drag force. Also, it shows effect of clearance between string and the wellbore. The smaller clearance between drillstring and openhole section shows greater viscous drag force in contrast with larger clearance between drillstring and cased hole. At a velocity of $1 \mathrm{ft} / \mathrm{sec}$, the flow regime will be laminar. Based on equations for the power-law model in Appendix A, when tripping speed is less than $4.5 \mathrm{ft} / \mathrm{sec}$ the flow regime is laminar in both cased and open holes. At a tripping speed of $5 \mathrm{ft} / \mathrm{sec}$ in openhole section the flow regime changes to transient flow and in cased 
hole remains laminar due to larger clearance. Table 2 shows the different flow regimes at different tripping speeds. Figure 18 shows the tripping speed effect on flow regime and hydrodynamic viscous drag force. By increasing tripping speed, the flow regime tends towards turbulent flow which increases value of viscous drag force drastically. Hydrodynamic viscous drag forces should be added to the calculated hook load during tripping out and also should be subtracted from calculated hook load during tripping in. In the cases analyzed in this paper the viscous drag is about one percent of the total hook load.

\section{Conclusions}

The soft string model presented in this paper consists of two sets of equations for straight and curved wellbore sections. The model is 3-dimentional which can consider the effects of build up or drop off bend combined with side bend, simultaneously.

The solutions presented in this paper are applicable for drilling and tripping in/out operations. Also the solutions are included for combined motions such as reaming and back reaming where the pipe is rotated and pulled or lowered at the same time.

The hydrodynamic viscous force can be applied during different operations. Two procedures with two sets of equations are presented for different fluid models such as power-law and Bingham-plastic.

A simple equation is presented for calculating the contact surface effect. It can be multiplied by the friction coefficient and used in all equations.

\section{Future Work}

Wellbore friction is a critical parameter not only to drill oil wells, but also during casing running and completion operations. Running the casing in long reach wells is usually one of the most critical operations. The main objective of this paper is to investigate several issues related to torque and drag modeling to use in torque and drag simulators. Torque and drag simulators are usually used during well planning and drilling operations to perform the following:

$>$ investigate if planned well path can be drilled and completed with available equipments,

$>$ feasibility of well design by ensuring rig sizing and drillstring optimization,

$>$ determining drilling restrictions for oilfield development,

$>$ using realtime mode to predict torque and drag online during drilling operation. It can be compared with measured hook load for any possible problems.

Based on this study, the torque and drag simulator should be included with the following options:

$>$ The modes for torque and drag calculation during drilling, tripping in/out, reaming and back reaming operation.

$>$ The modes for active and inactive dead line sheave to control the quality of measured hook loads.

$>$ The modes for different drilling fluid models to calculate hydrodynamic viscous drag force during pulling and lowering the string.

The modes to include contact surface effect during torque and drag calculations.

\section{Nomenclature}

$\begin{array}{ll}C_{C} & \text { mud clinging constant } \\ C_{S} & \text { contact surface correction factor } \\ d & \text { string outer diameter, in } \\ D & \text { wellbore diameter, in } \\ e & \text { sheave efficiency } \\ E & \text { modulus of elasticity, } l b f / \mathrm{in}^{2} \\ F_{I} & \text { force at the bottom, } l b \\ F_{2} & \text { force at the top, } l b \\ F_{D} & \text { drag force, } l b \\ F_{d l} & \text { dead line tension, } l b \\ F_{N} & \text { normal force, } \mathrm{lb} \\ i & \text { top of element } \\ i-1 & \text { bottom of element }\end{array}$


$k \quad$ consistency index, dyne.s $/ 100 \mathrm{~cm}^{2}$

$L \quad$ pipe length, $f t$

$n \quad$ flow-behavior index

$N \quad$ number of drilling lines

$N_{r} \quad$ rotary pipe speed, $r p m$

$N_{R e} \quad$ Reynolds's number

$P \quad$ pressure, $p s i$

$P V \quad$ plastic viscosity, $c p$

$r \quad$ pipe/connection radius, in

$R \quad$ radius of curvature, $f t$

$t \quad$ pipe wall thickness, in

$T \quad$ torque in string, $l b . f t$

$V \quad$ velocity, $\mathrm{ft} / \mathrm{sec}$

$V_{h} \quad$ hoisting velocity, $\mathrm{ft} / \mathrm{sec}$

$V_{r} \quad$ rotational velocity, $\mathrm{ft} / \mathrm{sec}$

$v_{a e} \quad$ average effective velocity, $\mathrm{ft} / \mathrm{sec}$

$v_{p} \quad$ tripping velocity, $\mathrm{ft} / \mathrm{sec}$

$w \quad$ unit pipe weight, $l b$

$W \quad$ total string weight, $l b$

$\alpha \quad$ wellbore inclination, $r a d$

$\beta \quad$ buoyancy factor

$\gamma \quad$ contact surface angle, $\mathrm{rad}$

$\delta \quad$ pipe-wellbore ratio

$\theta \quad$ absolute change in direction, rad

$\mu \quad$ coefficient of friction

$\rho \quad$ density, $l b /$ gallon

$\psi \quad$ angle between axial and tangential pipe velocities, rad

$\varphi \quad$ wellbore azimuth, $\mathrm{rad}$

\section{References}

Aadnoy, B.S. \& Andersen, K. (2001). Design of Oil Wells Using Analytical Friction Models. Journal of Petroleum Science and Engineering, 32, 53-71.

Aadnoy, B.S., Fazaelizadeh, M. \& Hareland, G., (2009). A 3-Dimentional Analytical Model for Wellbore Friction, Journal of Canadian Petroleum Technology, Submitted in October.

Burkhardt, J.E. (1960). Wellbore Pressure Surges Produced by Pipe Movement. Society of Petroleum Engineers. Annual Conference in Denver, October 2-5, 1546.

Dangerfield, J.W. (1987) .Analysis Improves Accuracy of Weight Indicator Readings. Oil and Gas Journal, August 10, 33.

Eek-Olsen, J., Drevdal, K.E., Samuell, J. \& Reynolds, J. (1994). Designing Directional Drilling to Increase Total Recovery and Production Rates. Society of Petroleum Engineers/International Association Drilling Contractors, Conference, Dallas, Texas, February 15 - 18, 27461.

Johancsik, C.A., Friesen, D.B. \& Dawson, R. (1984). Torque and Drag in Directional Wells - Prediction and Measurement. , Journal of Petroleum Technology, June, pp. 987 - 992.

Luke, G.R., Juvkam-Wold, H.C. (1993). Determination of True Hook Load and Line Tension under Dynamic Conditions. Journal of SPE Drilling and Completion, December, pp. 259-264.

Maidla, E.E., Wojtanowicz, A.K.(1987,a).Field Method of Assessing Borehole Friction for Directional Well Casing., Society of Petroleum Engineers, SPE Middle East Oil Show, Manama, Bahrain, March 7-10, 15696. 
Maidla, E.E., Wojtanowicz, A.K. (1987,b). Field Comparison of 2-D and 3-D Methods for the Borehole Friction Evaluation in Directional Wells., Society of Petroleum Engineers. $62^{\text {nd }}$ SPE Annual Technical Conference, Dallas, Texas September 7-10, 16663.

Mason, C.J. \& Chen, D.C.K. (2007). Step Changes Needed To Modernize T\&D Software. Society of Petroleum Engineers. SPE/IADC Drilling Conference, Amsterdam, Netherland, February 20-22, 104609.

Mitchell, R.F \& Samuel, R. (2007). How Good is the Torque-Drag Model? . Society of Petroleum Engineers. SPE/IADC Drilling Conference. Amsterdam, Netherland, February 20-22, 105068.

Payne, M.L., Cocking, D.A. \& Hatch, A.J. (1994). Critical Technologies for Success in Extended Reach Drilling. Society of Petroleum Engineers. SPE Annual Conference and Exhibition. New Orleans, Louisiana25-28 September, 28293.

Sheppard, M.C., Wick, C. \& Burgess, T., (1987) .Designing Well Paths to Reduce Drag and Torque. Journal of SPE Drilling Engineering, December, pp. 344-350.

\section{Tables}

Table 1. Different situations for combined motion

\begin{tabular}{|c|c|c|c|c|c|c|}
\hline No. & Condition & Rotational Speed & Axial Speed & Torque & Drag & $\begin{array}{c}\text { Operation } \\
\text { Mode }\end{array}$ \\
\hline 1. & $\psi=0$ & $0<$ & $=0$ & Maximum & $=0$ & Drilling \\
\hline 2. & $0 \prec \psi \prec 90$ & $0<$ & $0<$ & $0<$ & $0<$ & $\begin{array}{c}\text { Reaming } \\
/ \text { Back } \\
\text { Reaming }\end{array}$ \\
\hline 3. & $\psi=90$ & $=0$ & $0<$ & $=0$ & Maximum & $\begin{array}{c}\text { Tripping } \\
\text { in/out }\end{array}$ \\
\hline
\end{tabular}

Table 2. Flow regimes for different drillstring position at different tripping speed

\begin{tabular}{|c|c|c|}
\hline Tripping speed, $\mathrm{ft} / \mathrm{sec}$ & Drillstring position & Flow Regime \\
\hline$<4.5$ & Cased Hole & Laminar \\
\hline$<4.5$ & Open Hole & Laminar \\
\hline 5 & Cased Hole & Transient \\
\hline 5 & Open Hole & . \\
\hline
\end{tabular}




\section{Figures}

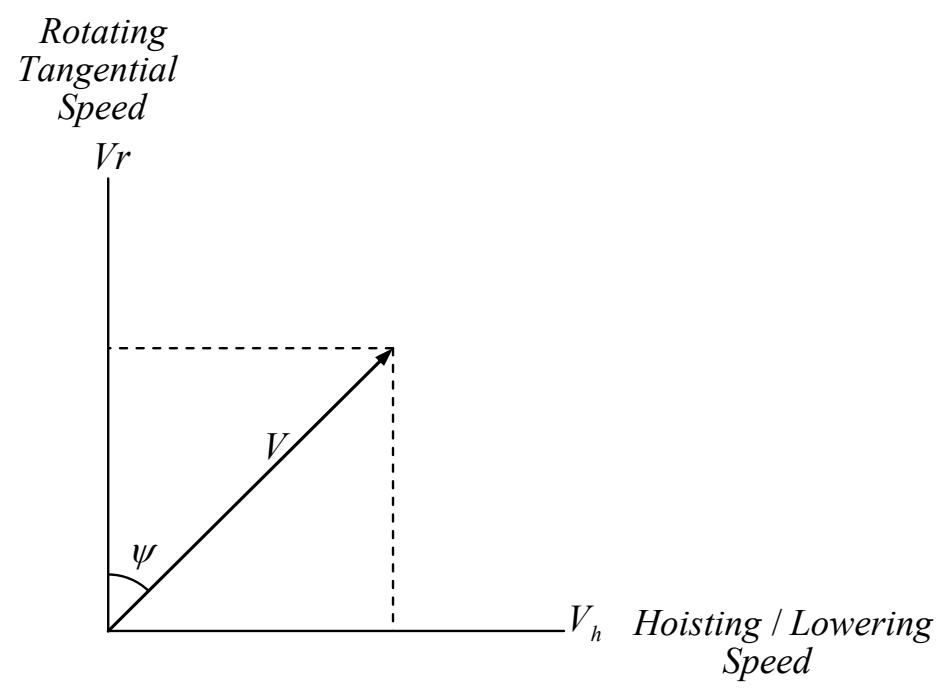

Figure 1. Resultant velocity of axial and tangential velocity

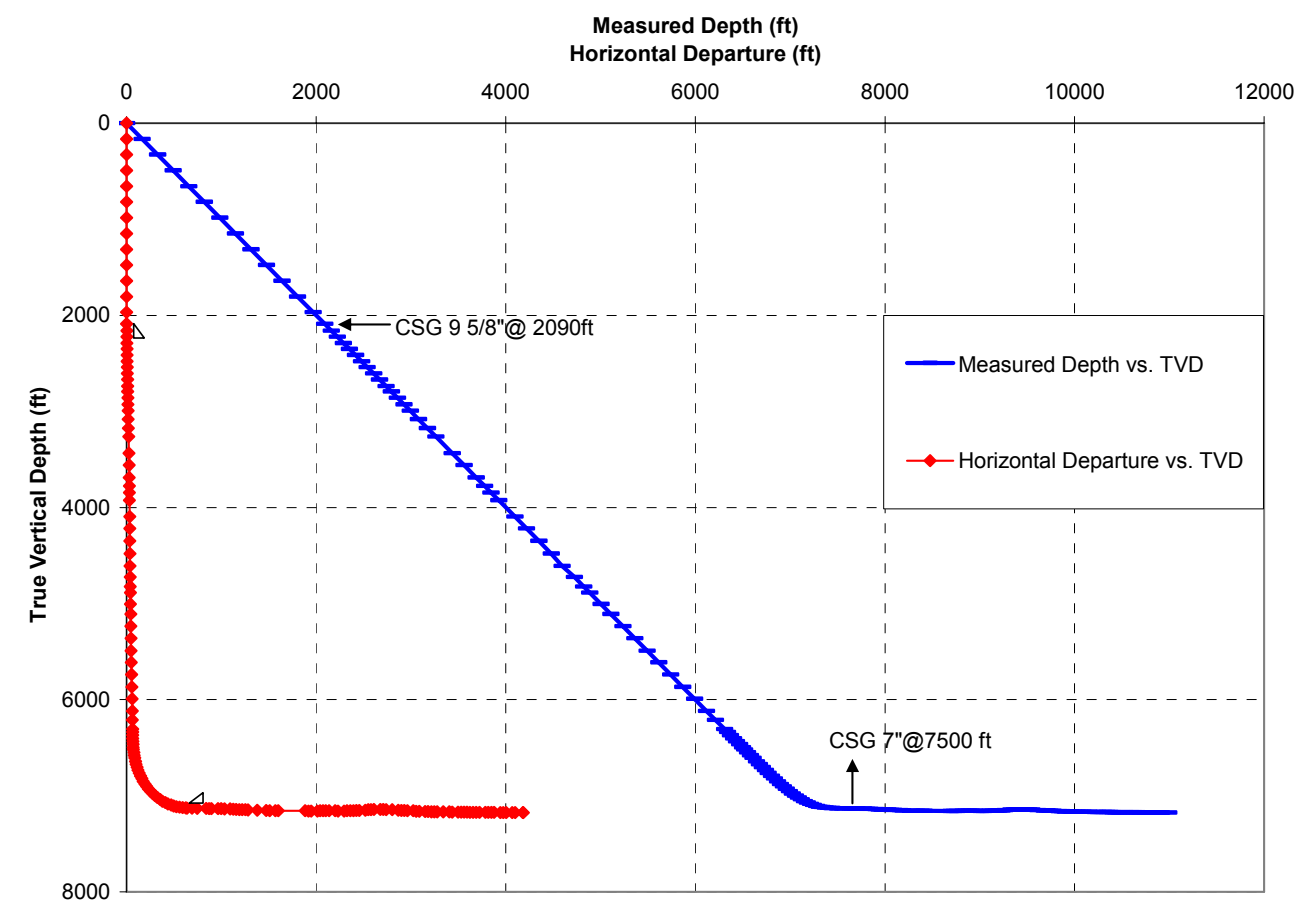

Figure 2. Geometry of the well 


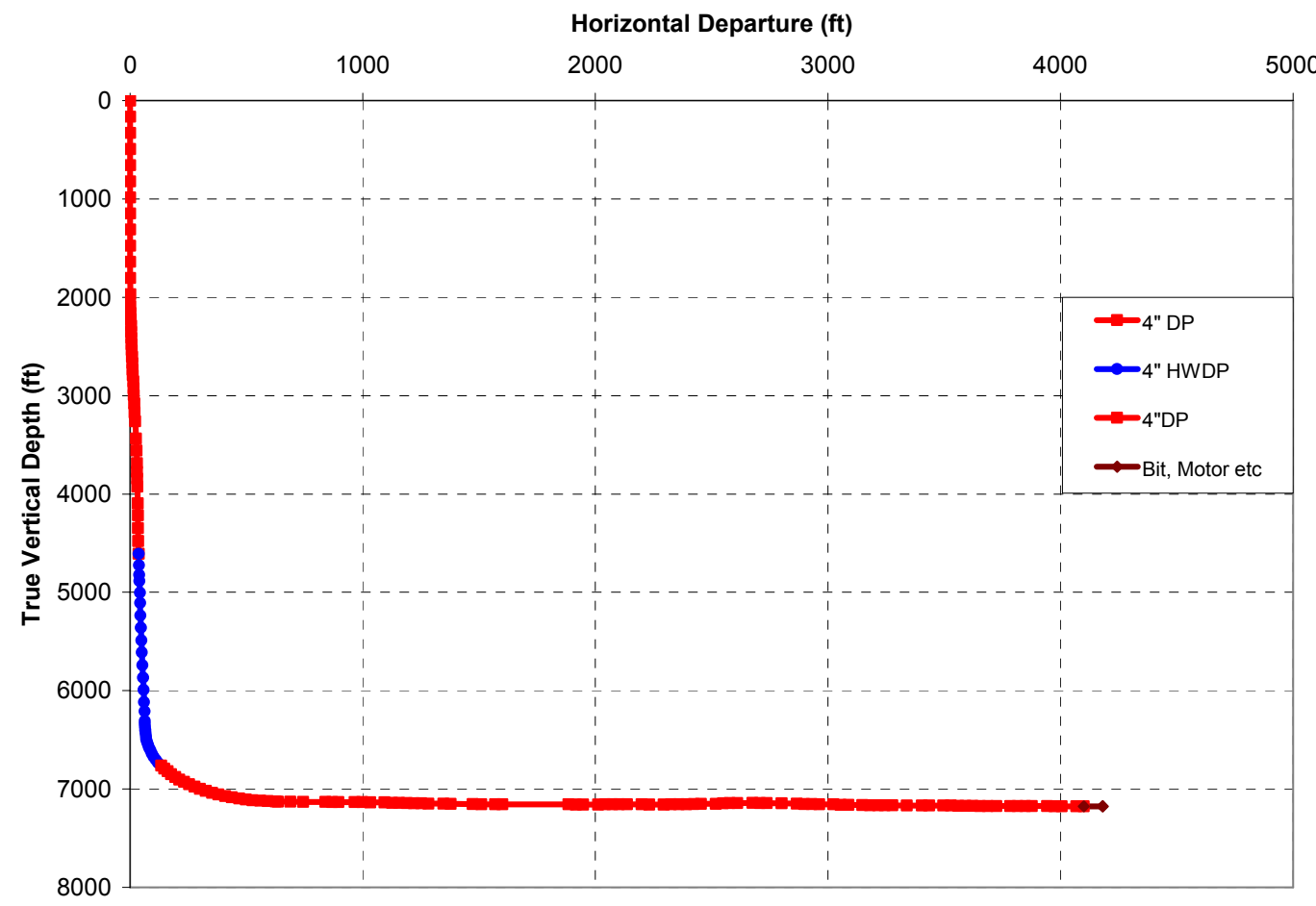

Figure 3. Drillstring configuration

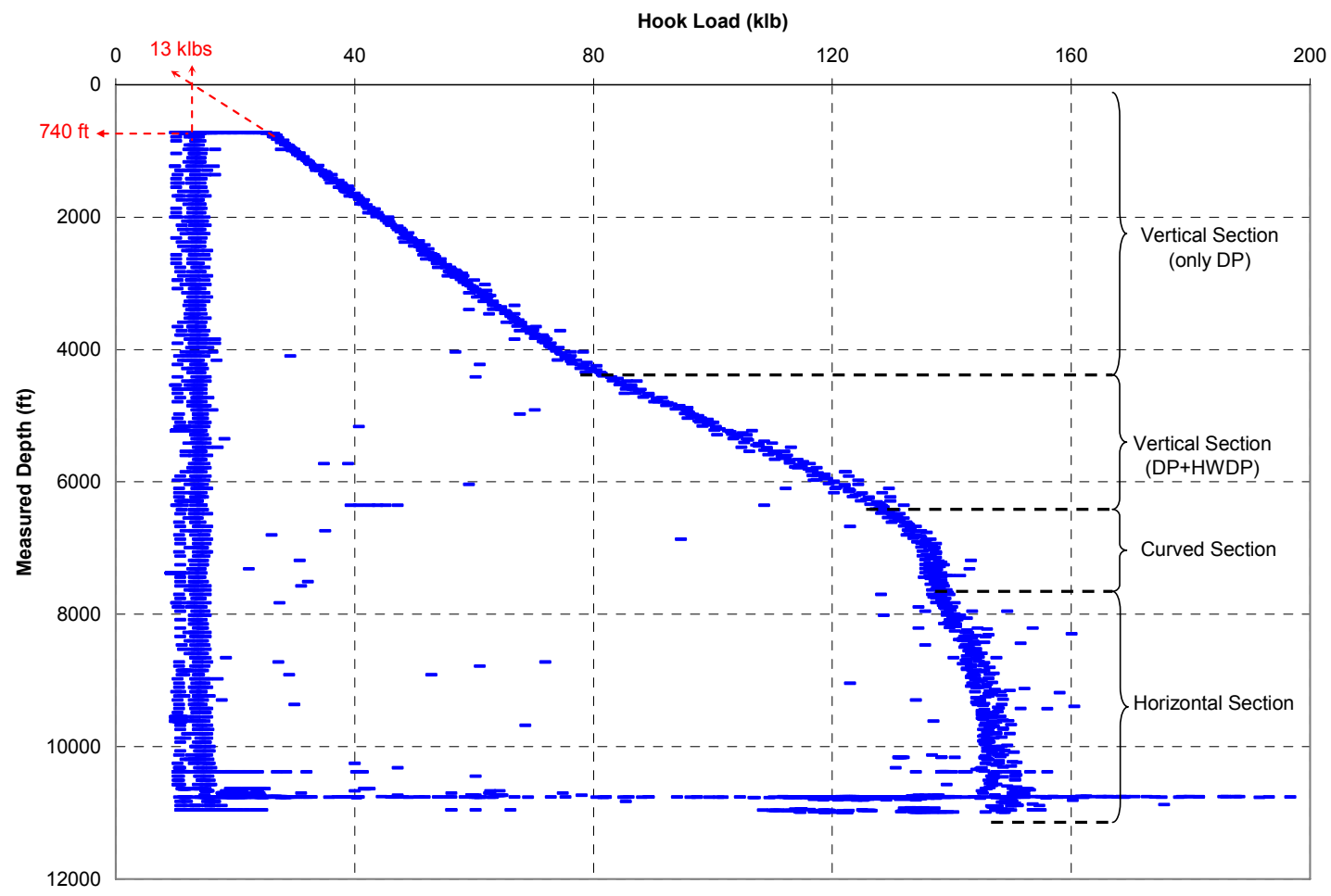

Figure 4. Measured hook load vs. measured depth while tripping out 


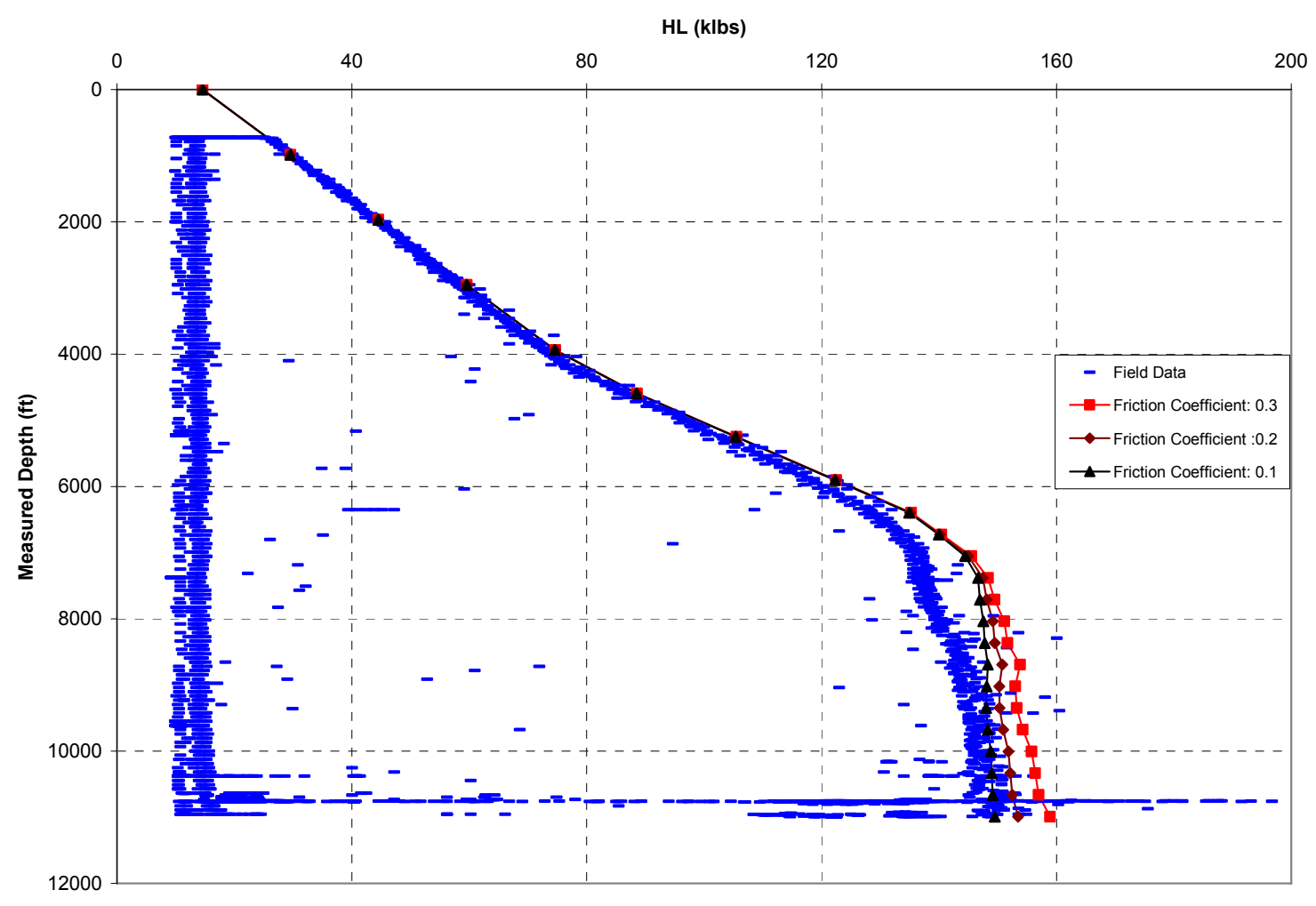

Figure 5. Comparison between measured and calculated hook loads while tripping out

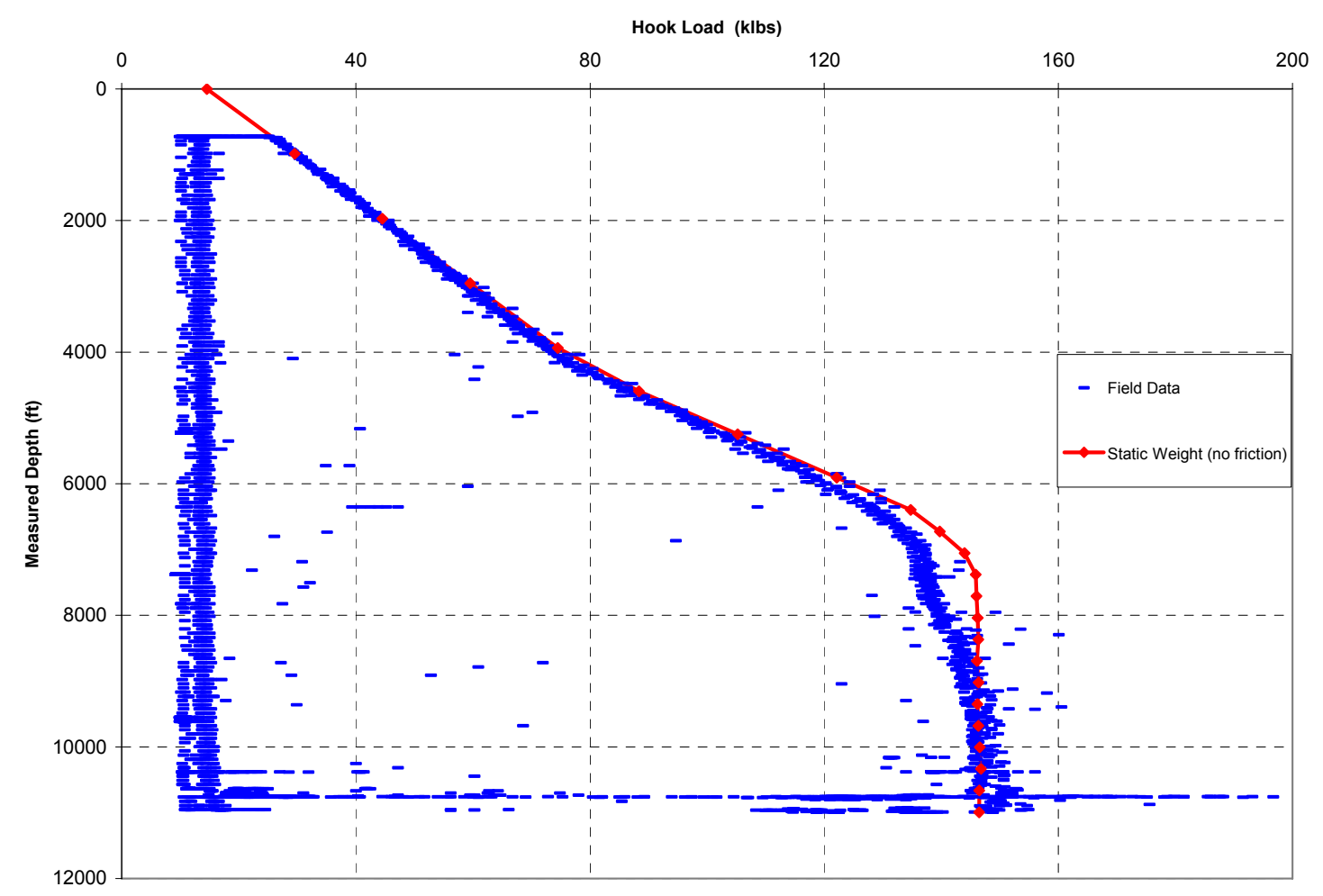

Figure 6. Comparison between measured hook loads while tripping out and calculated static weight data 


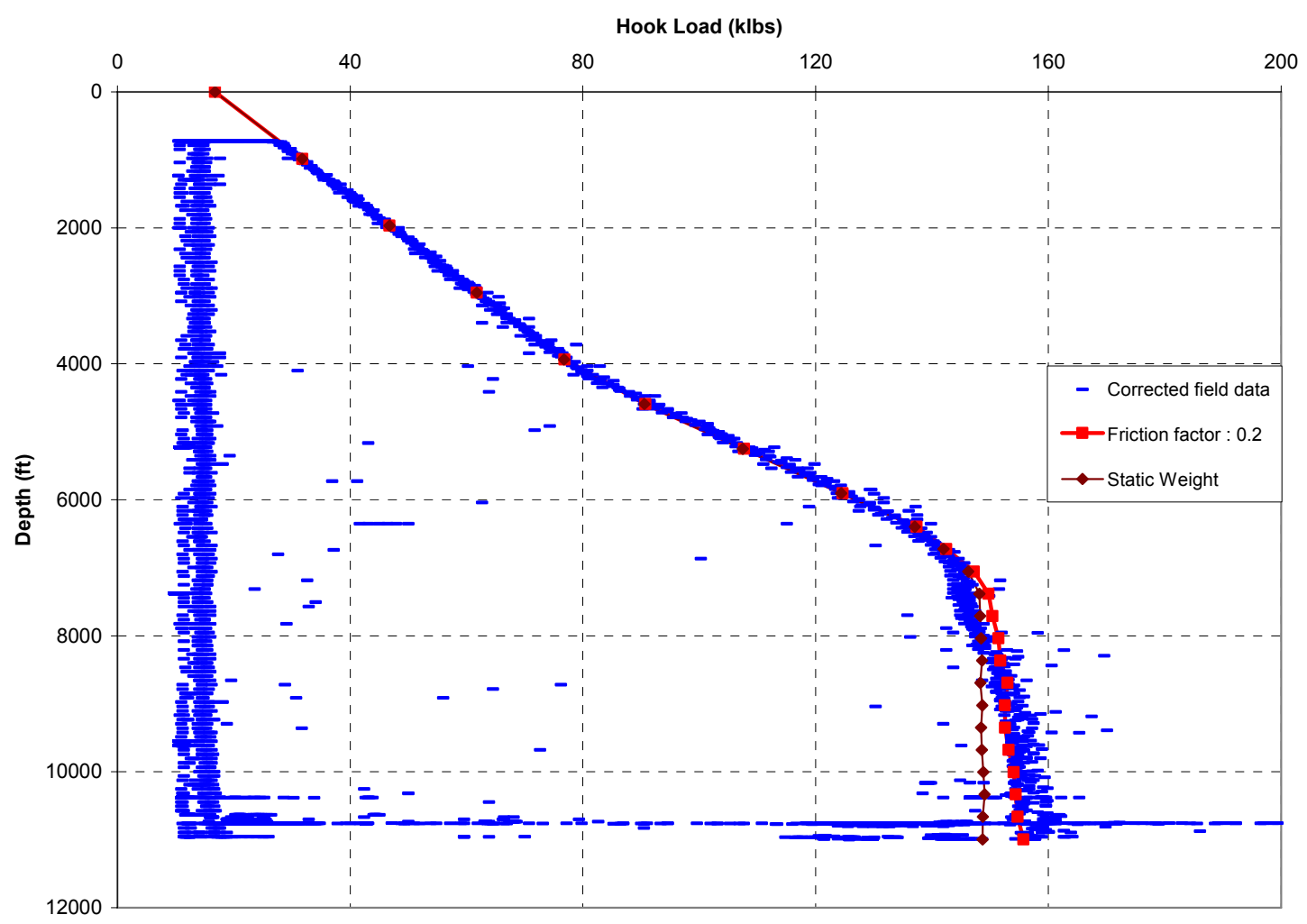

Figure 7. Comparison between corrected field data and modeling results for tripping out

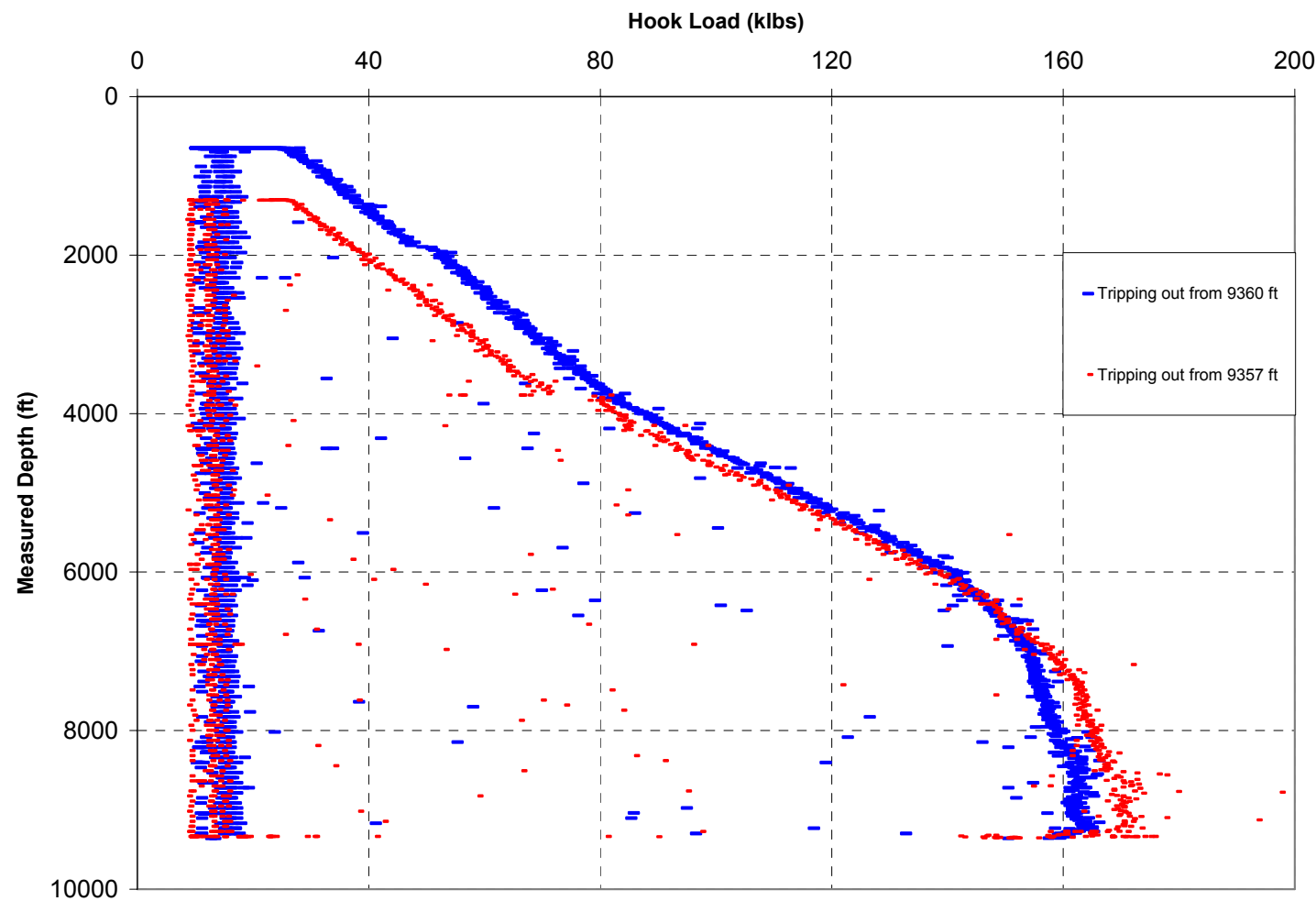

Figure 8. Comparison between two subsequent measured hook loads while tripping out 


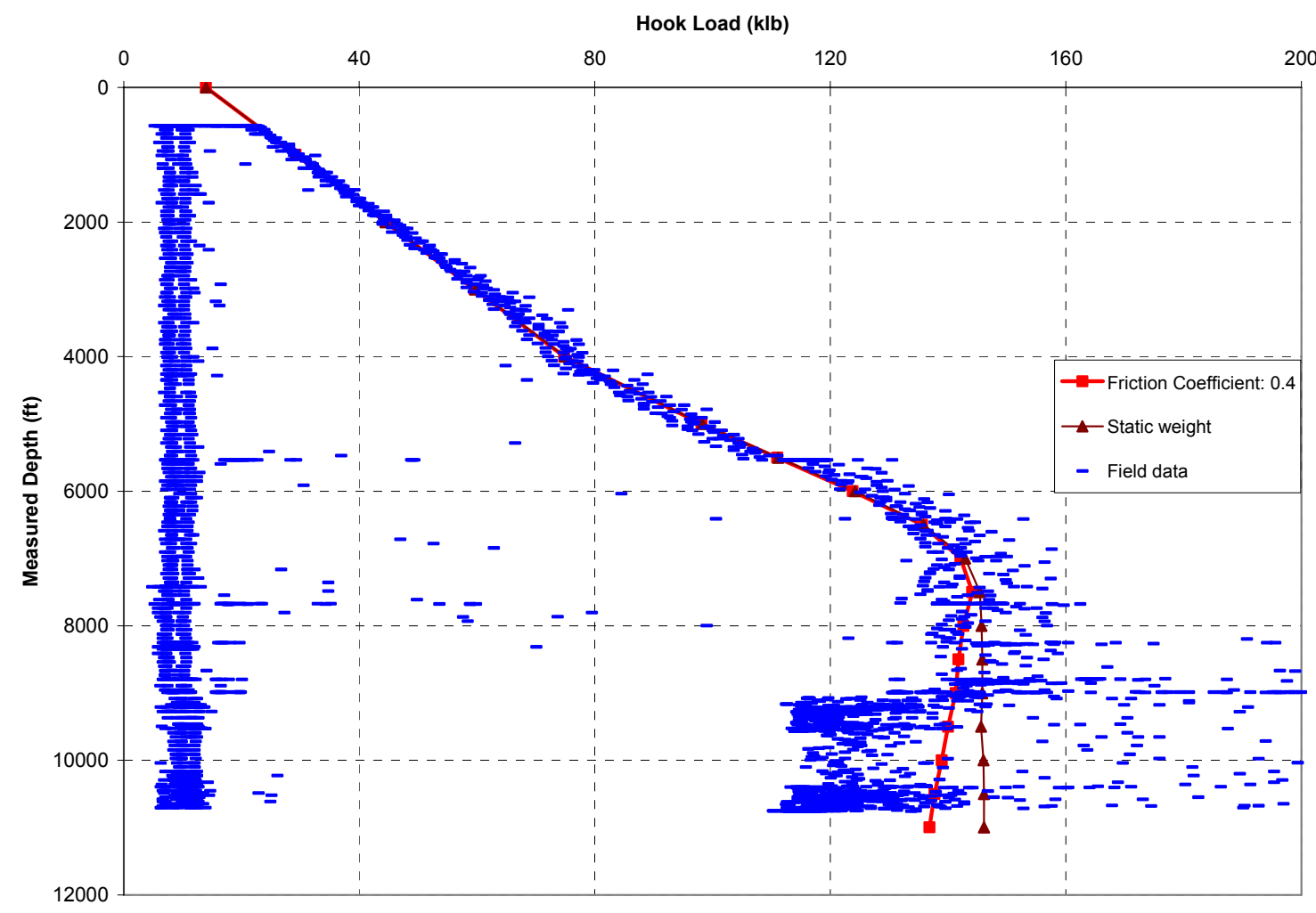

Figure 9. Comparison between measured and calculated hook loads while tripping in

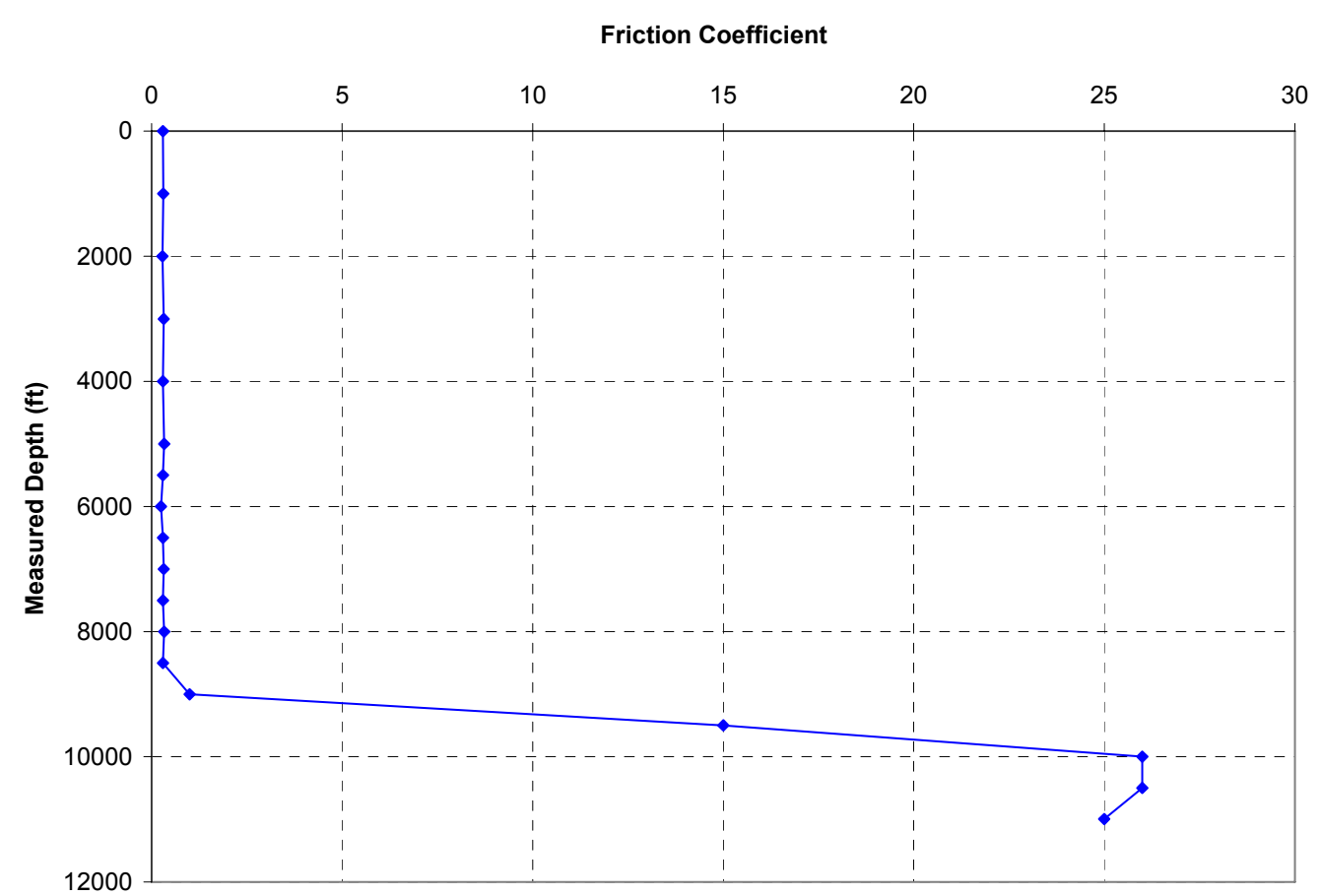

Figure 10. Sensitivity analysis of friction coefficient vs. measured depth while tripping in 


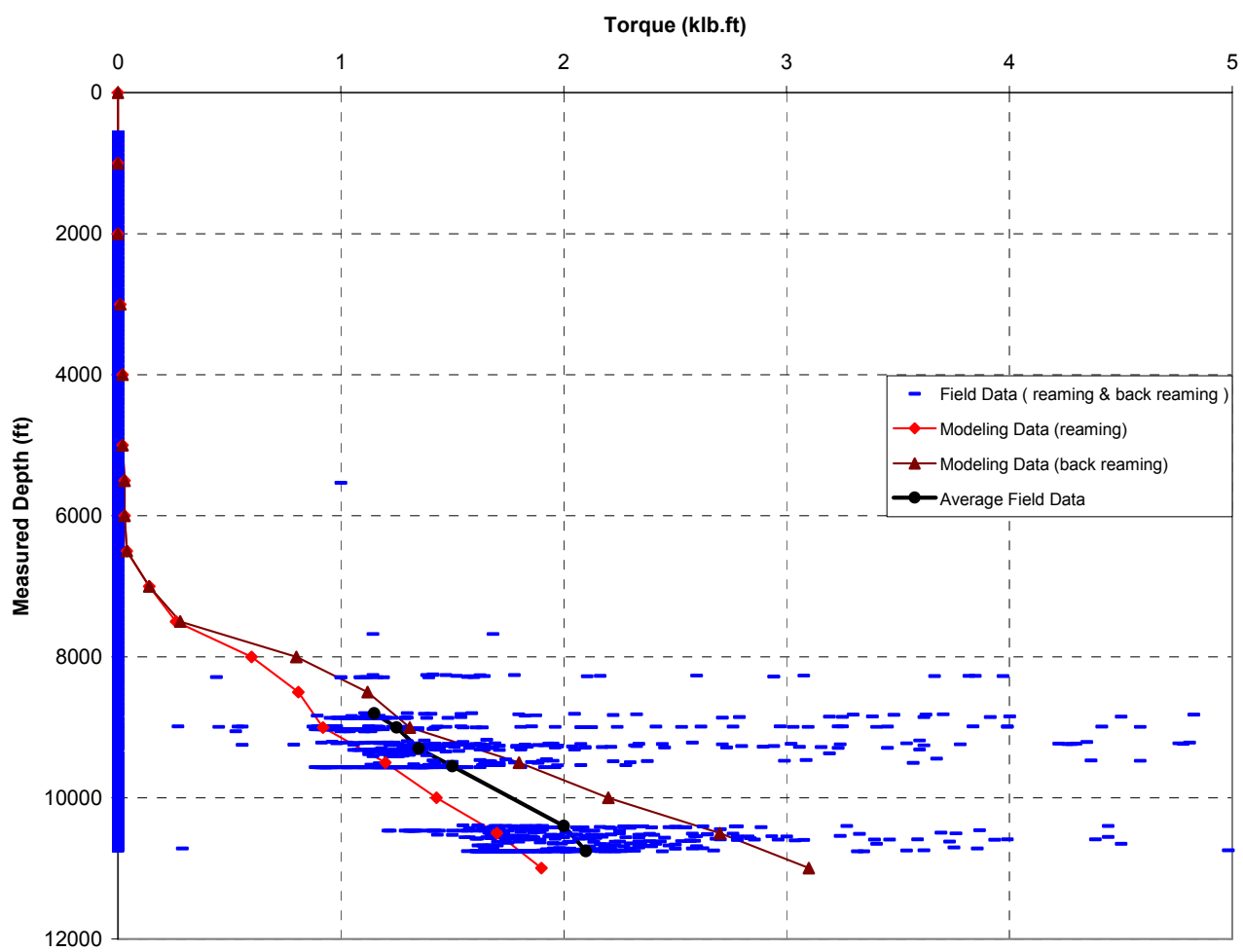

Figure 11. Comparison between measured and calculated surface torque while reaming and back reaming

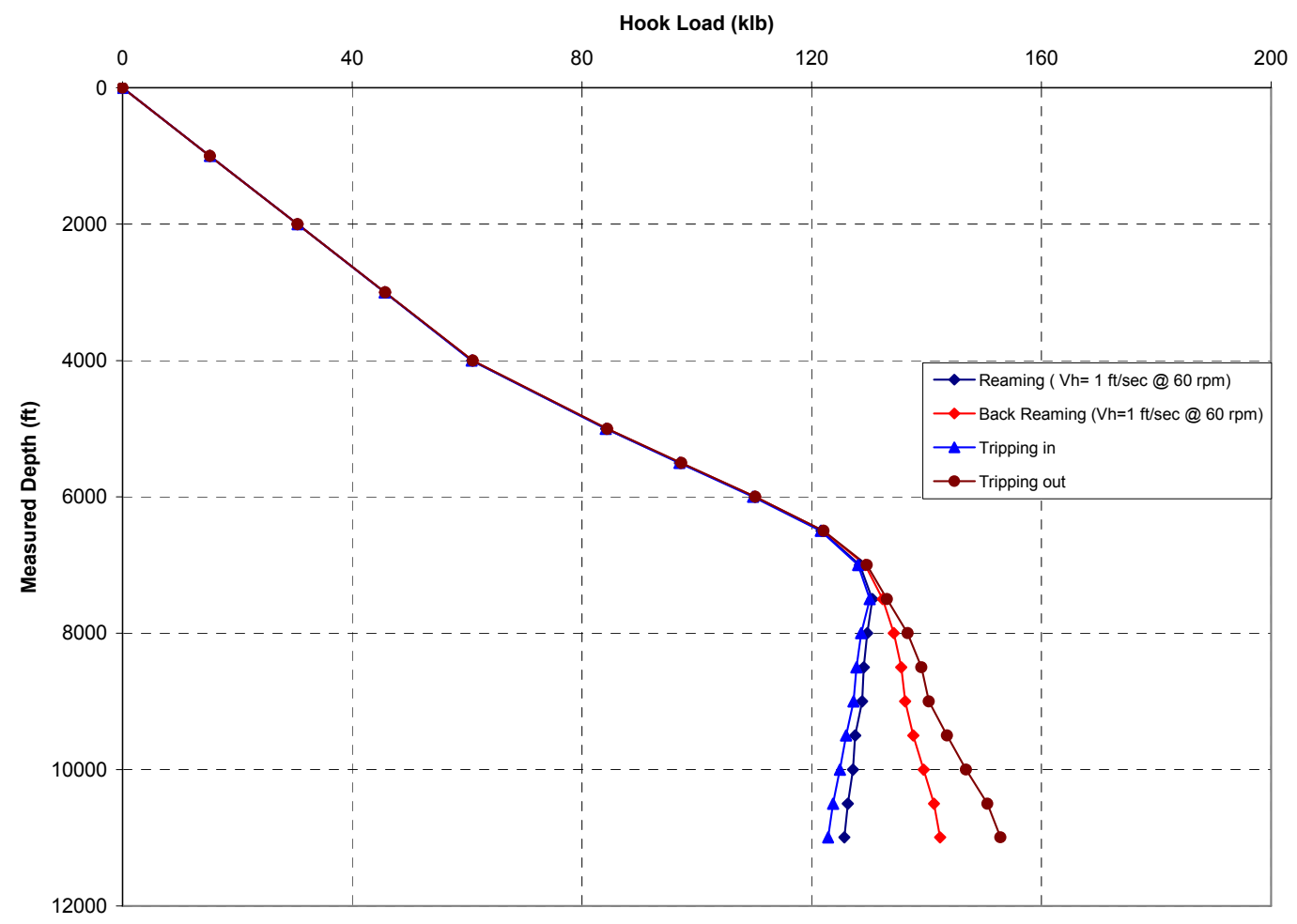

Figure 12. Effect of pipe rotation on calculated hook load while tripping in/out 


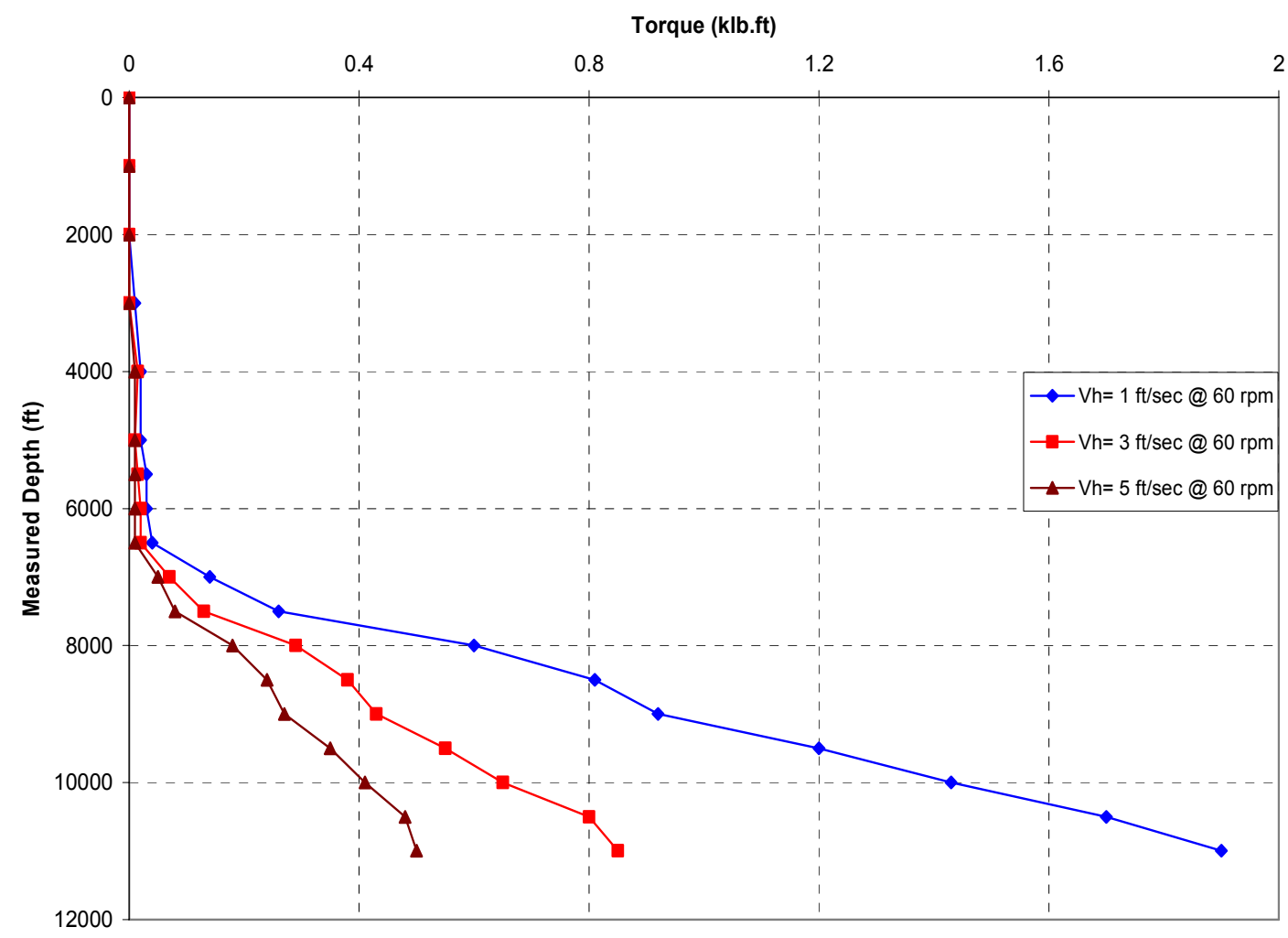

Figure 13. Effect of tripping speed on calculated torque while reaming operation

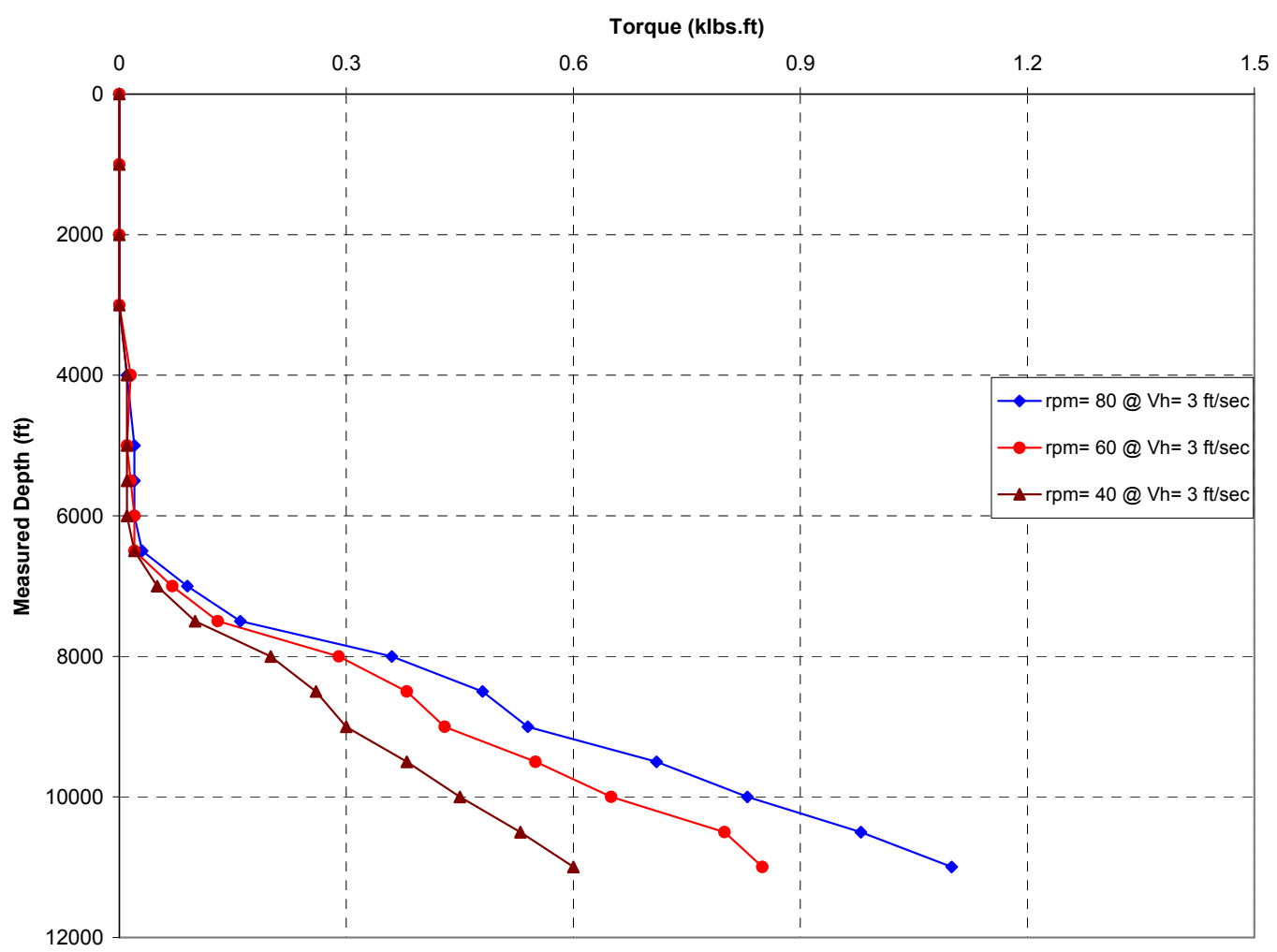

Figure 14. Effect of pipe rotation on calculated torque values while reaming operation 


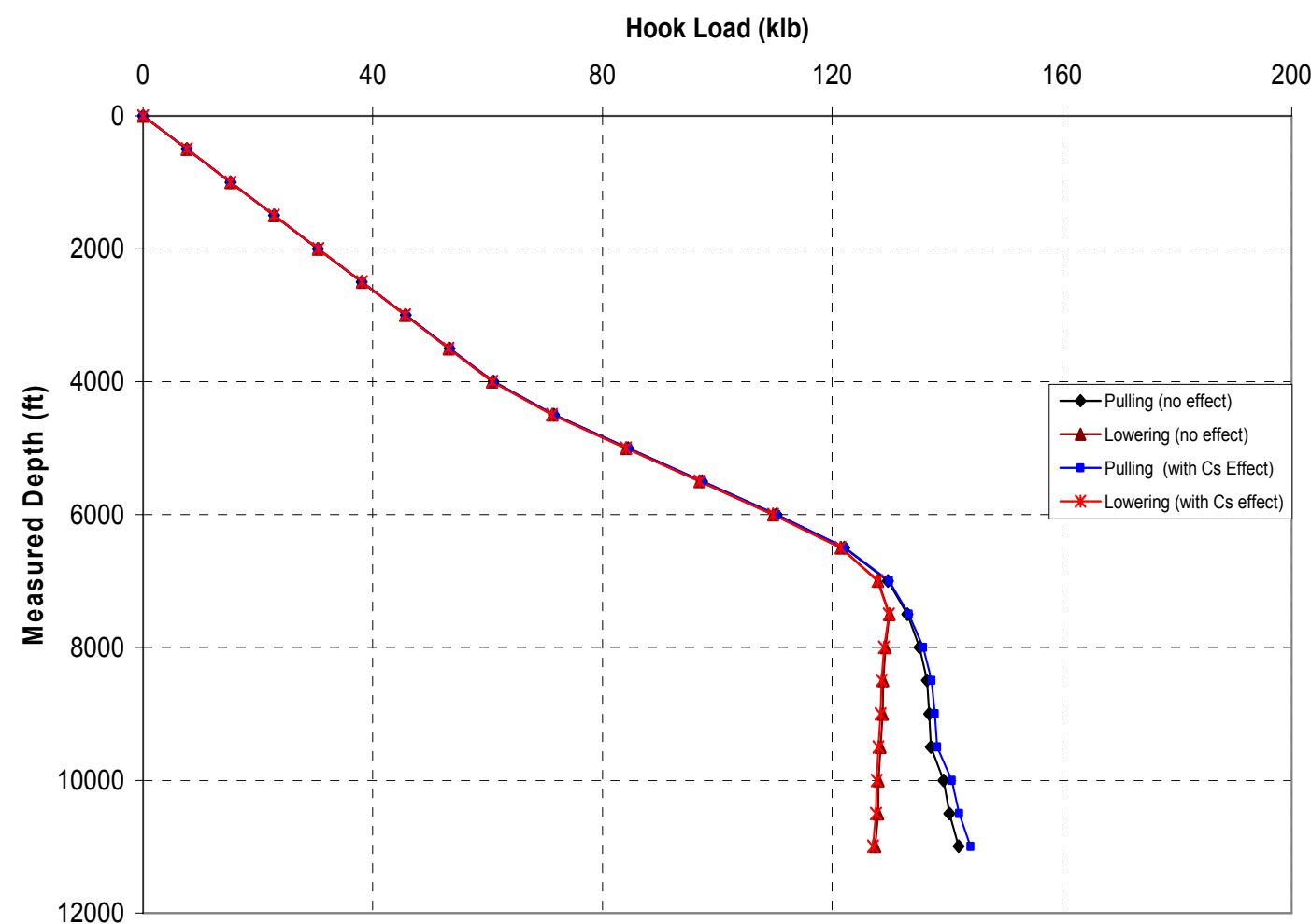

Figure 15. Effect of contact surface on calculated drag values while tripping in/out

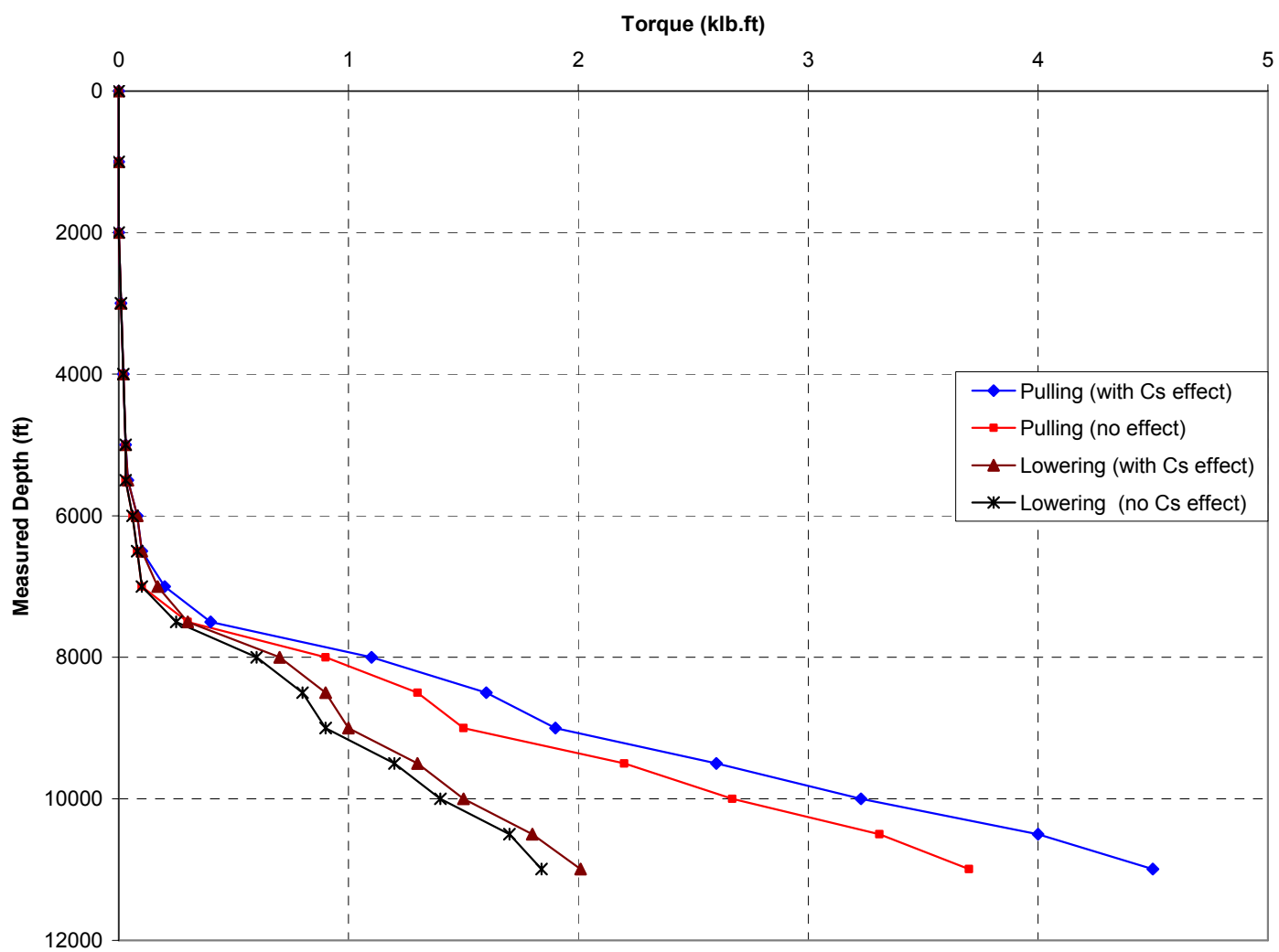

Figure 16. Effect of contact surface on calculated torque values while tripping in/out 


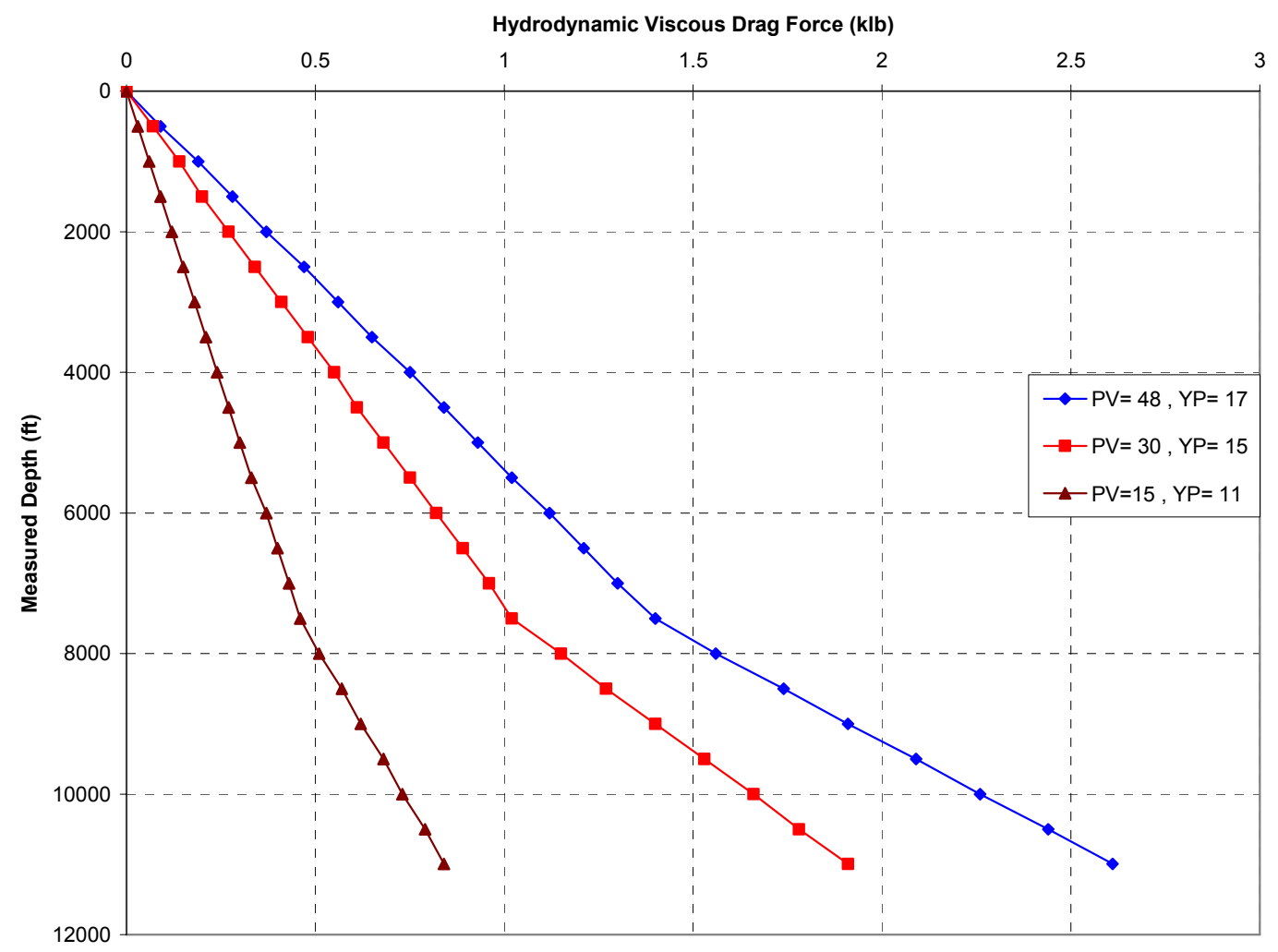

Figure 17. Effect of mud rheology and pipe string clearance on hydrodynamic viscous drag force

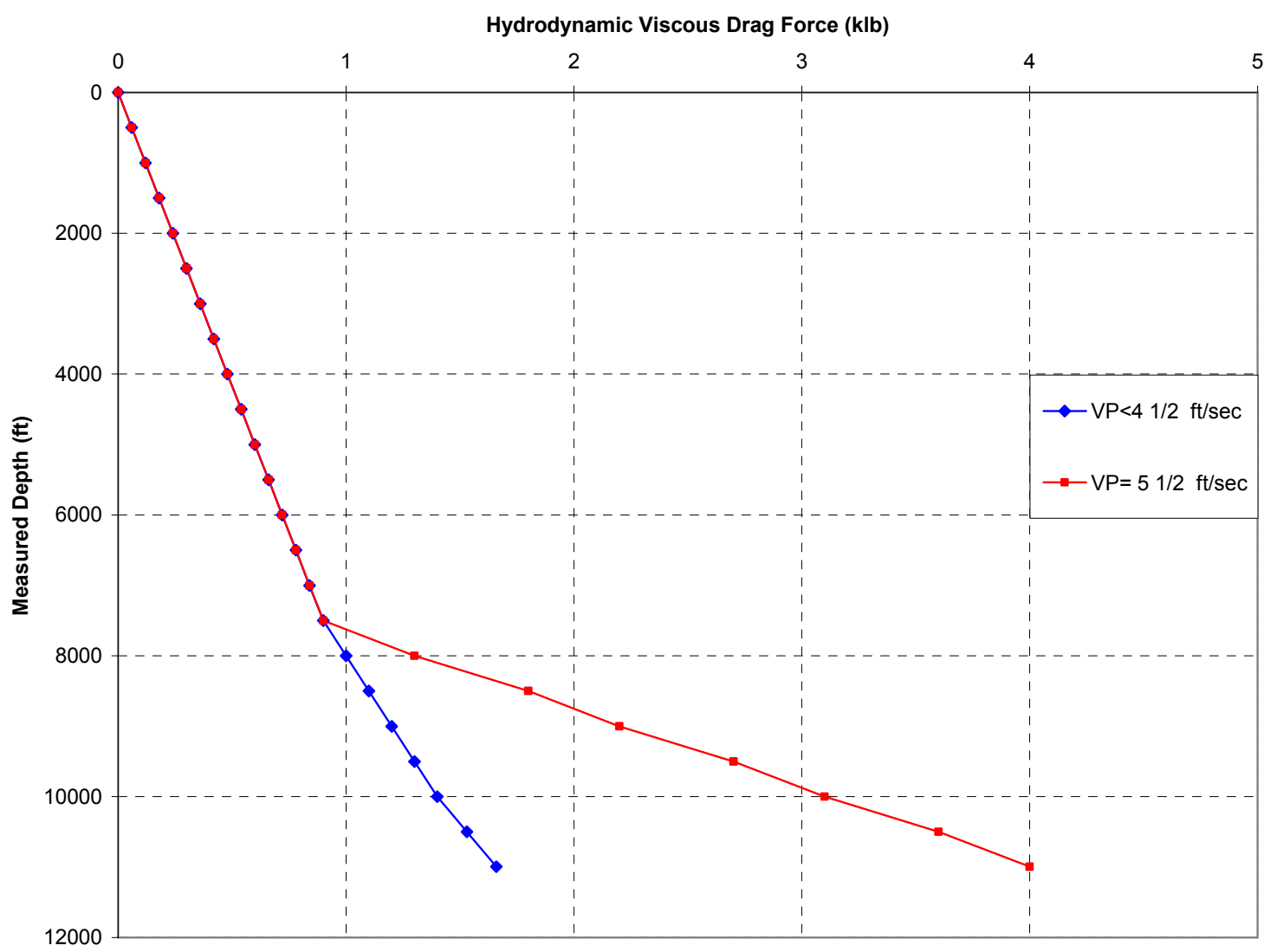

Figure 18. Effect of tripping speed and flow regime on hydrodynamic viscous drag force 


\section{Appendix A}

The calculation procedure for viscous pressure gradient is based on the theory of viscous drag for Bingham-plastic and Power-Law fluids in wellbores. These equations presented by Maidla and Wojtanowicz (1987, a) are applicable only for close end strings. The calculation procedure includes:

1. Calculation of mud clinging constant: The value of effective mud velocity due to moving pipe wall is related to pipe velocity by proportionality constant $C_{c}$. The value of $C_{c}$ depends upon the ratio of pipe and hole diameters.

For laminar flow

$C_{c}=\frac{\delta^{2}-2 \delta^{2} \ln \delta-1}{2\left(1-\delta^{2}\right) \ln \delta}$

for turbulent flow

$C_{c}=\frac{\sqrt{\frac{\delta^{4}+\delta}{1+\delta}}-\delta^{2}}{1-\delta^{2}}$

Where $\delta$ represents the ratio of the pipe diameter to the borehole diameter

2. Calculation of the average effective annular velocity: It is the mud velocity which produces the viscous drag component of surge pressure and its frame of references is the wellbore wall which defined by Burckhardt (1961).

$v_{a e}=v_{p} \times\left(\frac{\delta^{2}}{1-\delta^{2}}+C_{c}\right)$

3. Calculation of Reynolds number $N_{\mathrm{Re}}$ for annular flow:

Bingham-plastic Model:

$N_{\mathrm{Re}}=926.4 \times \frac{(D-d) v_{a e} \rho}{P V}$

Laminar flow: $\quad N_{\mathrm{Re}} \leq 2100$

Turbulent flow: $\quad N_{\mathrm{Re}} \succ 2100$

Power-law Model:

$N_{\mathrm{Re}}=10.9 \times 10^{4} \frac{\rho v_{a e}^{2-n}}{k}\left(\frac{D-d}{48} \times \frac{n}{2 n+1}\right)^{n}$

Laminar flow: $\quad N_{\mathrm{Re}} \leq 3470-1370 \times n$

Turbulent flow: $\quad N_{\mathrm{Re}} \geq 4270-1370 \times n$

4. Calculation of friction factor: For smooth pipe and a Reynolds numbers less than $10^{5}$, a straight line approximation of the Colebrook function for Bingham-plastic fluid yields accurate friction factor. It is known as fanning friction factor. For Power-law fluids, due to low Reynolds numbers for surges, it is also possible to use the fanning friction factor with acceptable errors. The Fanning equations are as follow:

Laminar flow:

$f=\frac{16}{N_{\mathrm{Re}}}$

Turbulent Flow:

$f=\frac{0.0791}{N_{\mathrm{Re}}{ }^{0.25}}$

5. Calculation of the viscous pressure gradients:

Bingham-plastic model was presented by Burckhardt (1961):

$\frac{\Delta P}{\Delta L}=\frac{f v_{a e}^{2} \rho}{25.78 \times(D-d)}$ 
Power-law model presented by (Maidla and Wojtanowicz, 1987, a):

Laminar flow:

$\frac{\Delta P}{\Delta L}=\frac{k}{14.4 \times 10^{4}(D-d)}\left(\frac{48}{D-d} \times \frac{2 n+1}{n}\right)^{n}$

Turbulent flow:

$\frac{\Delta P}{\Delta L}=\frac{f v a e^{2} \rho}{21.1 \times(D-d)}$

\section{Appendix B}

For calculating contact surface angle, the following procedure presented by Maidla and Wojtanowicz (1987, a) should be used:

$\gamma_{i}=\left|\operatorname{Arctan}\left(\frac{2 X_{i}}{2 Y_{i}-D_{i}+d_{i}}\right)\right|$

Where:

$Y_{i}=\frac{1}{4} \times\left|\frac{D_{i}^{2}-d^{2}{ }_{i}+\left(D_{i}-d_{i}+2 \Delta d_{i}\right)^{2}}{\left(D_{i}-d_{i}+2 \Delta d_{i}\right)}\right|$

$X_{i}=\frac{1}{2} \times\left|d_{i}^{2}-4 Y_{i}^{2}\right|^{\frac{1}{2}}$

$\Delta d_{i}=\frac{\pi}{24 E_{i}} \times\left\{\left(\beta w_{i} \cos \theta_{i}\right)^{2}+\left(\beta w_{i} \sin \alpha_{i}+\frac{F_{i-1}}{R_{i}}\right)^{2}\right\}^{\frac{1}{2}} \times \frac{d_{i}}{t_{i}}$

The values of $\Delta d$ are negligible due to big value of modulus elasticity of steel which is $30^{*} 10^{6}$ psi. Its ignorance will not effect on value of $C s_{i}$. If the $\Delta d$ is ignored, $C s_{i}$ will be only the function of wellbore diameter and string outer diameter and can be rewritten as follow:

$C s_{i}=\frac{2}{\pi} \times \operatorname{Arctan}\left(\frac{\left(D_{i}^{2}-d_{i}^{2}\right)^{\frac{1}{2}}}{d_{i}}\right) \times\left(\frac{4}{\pi}-1\right)+1$

\section{Appendix C}

The following equations presented by Luke and Juvkam-wold (1993), include direction of drillstring movement and type of dead line sheave for true hook load prediction. For inactive (frictionless) dead line sheave, when tripping drillstring out, the hook load can be calculated as follow,

$W=F_{d l} \times \frac{e\left[1-\left(1 / e^{N}\right)\right]}{(e-1)}$

When tripping in:

$W=F_{d l} \times \frac{\left(1-e^{N}\right)}{(1-e) e^{N}}$

For active (friction) dead line sheave, when pulling drillstring out, the hook load will be as follow:

$W=F_{d l} \times \frac{\left(1-e^{N}\right)}{(1-e) e^{N}}$

For tripping drillstring in, the hook load is:

$W=F_{d l} \times \frac{e\left(1-e^{N}\right)}{(1-e)}$ 